\title{
Loanable funds versus money creation in banking: a benchmark result
}

\author{
Salomon Faure ${ }^{1} \cdot$ Hans Gersbach ${ }^{2}$
}

Received: 14 January 2021 / Accepted: 24 May 2021 / Published online: 11 January 2022

(C) The Author(s) 2022

\begin{abstract}
We establish a benchmark result for the relationship between the loanable-funds and the money-creation approach to banking. In particular, we show that both processes yield the same allocations when there is no uncertainty. In such cases, using the much simpler loanable-funds approach as a shortcut does not imply any loss of generality. When there is aggregate risk with complete contracts and complete markets, we indicate that a restricted equivalence result holds.
\end{abstract}

Keywords Money creation · Bank deposits - Capital regulation · Monetary policy $\cdot$ Loanable funds

JEL Classification D50 - E4 · E5 - G21

\section{Introduction}

\subsection{Motivation, approach, and main insight}

Most models of banking - be they micro- or macro-oriented-are based on the socalled "loanable-funds approach to banking": Banks are financed through deposits, equity, and other financial contracts, and then they lend to firms or buy assets. In our monetary architecture, however, the opposite process is at work. Banks start lending

Hans Gersbach

hgersbach@ethz.ch

Salomon Faure

salomon.faure@gmail.com

1 CER-ETH - Center of Economic, Research at ETH Zurich, Zürichbergstrasse 18, 8092 Zurich, Switzerland

2 CER-ETH - Center of Economic, Research at ETH Zurich and CEPR, Zürichbergstrasse 18, 8092 Zurich, Switzerland 
to firms and simultaneously create deposits which are nominal contracts with claims on central bank money. Firms use deposits to buy investment goods, and deposits flow to households who decide about their portfolio of bank deposits, bank equity, and other assets they want to hold. Subsequently, households buy consumption goods, and deposits are transferred back to firms who repay their loans. This approach is called the "money-creation approach to banking."

In which circumstances do the money-creation approach and the loanable-funds approach yield the same outcomes? In our paper, we establish a simple benchmark result. In the absence of uncertainty, both processes yield the same allocation and no bank default occurs. Hence, in such cases, using the loanable-funds model as a shortcut does not imply any loss of generality.

More specifically, we develop the result in a simple two-period general equilibrium model in which a fraction of firms has to rely on banks to obtain physical goods since the firms cannot pledge to repay their bonds. The other firms are financed through the bond market. There is no production risk. We consider two different financing architectures of the economy. In both architectures, households decide on consumption and savings in the first period. The latter is split into bank deposits, bank equity, and bonds. Firms obtain loans to undertake production through banks and the bond market. In the loanable-funds approach, the households' savings, in the form of bank deposits and bank equity, are lent to some firms. In the money-creation approach, however, bank lending creates the deposits that are necessary for households to invest in bank deposits and bank equity.

In order to establish our benchmark result, we deliberately assume favorable manifestations of some other potential frictions and distortions in the economy. In particular, we make the following assumptions:

- Banks act as delegated monitors and can eliminate moral hazard problems of firms that do not obtain financing in the capital market. ${ }^{1}$ Banks are therefore essential for the financing of a fraction of firms. For simplicity, we set monitoring costs to zero. ${ }^{2}$

- When a government bail-out is needed, the required taxation of households is lump-sum and therefore does not lead to additional distortions.

We show that under these circumstances, both the money-creation approach and the loanable-funds approach yield the same allocation and no bank default occurs in equilibrium. Bank defaults may occur out-of equilibrium. Hence, in the absence of production risk and together with the manifestation of frictions outlined above, using the loanable-funds model as a shortcut does not imply any loss of generality. In the extension, we indicate that when there is aggregate risk with complete contracts and complete markets, a restricted equivalence result holds in the following sense: There is an equilibrium in the money-creation model that replicates

\footnotetext{
1 Such entrepreneurs then only play the passive role of running the technology. Also, there is no moral hazard on the part of bank managers monitoring entrepreneurs in the basic model.

2 This assumption is not essential and we could add the same monitoring costs per unit of loan in both the loanable-funds and the money-creation approach.
} 
the investment and consumption allocation in the equilibrium of the loanable-funds model, but the set of equilibria in both models differ.

\subsection{Relation to the literature}

Our work relates to two rather recent analytical papers. ${ }^{3}$ Jakab and Kumhof (2015) use a DSGE model to compare the money-creation approach with the loanablefunds approach to establish differences and similarities. In particular, they predict that in the money-creation approach, shocks to the creditworthiness of bank borrowers have a more pronounced and more immediate impact on the amount of outstanding bank loans and on output than in the loanable-funds version of the same model. Faure and Gersbach (2021) investigate the welfare properties of a general equilibrium model with bank money creation and an aggregate productivity shock. They demonstrate that the level of money creation is first-best in symmetric equilibria when prices are flexible, but that it is not necessarily first-best in asymmetric equilibria. Moreover, they show that when prices are rigid, there may be circumstances for which money creation by banks is not bounded. In such cases, the monetary system breaks down. Faure and Gersbach (2021) prove that capital requirements may restore the existence of equilibria with finite money creation, and in some cases, may even implement the first-best allocation.

In the present paper, we develop a model to study constellations when the loanable-funds approach and the money-creation approach to banking might deliver similar results. ${ }^{4}$ For this purpose, we use a two-sector macroeconomic model, but we abstract from any type of uncertainty. More specifically, the model is much more general than in Faure and Gersbach (2021), as it incorporates consumption/ investment choices and it replaces the linear production function in one of the sectors with a concave production function. However, the present model is more restricted than in Faure and Gersbach (2021), as it assumes away any type of uncertainty, which will ensure that default does not occur in equilibrium. ${ }^{5}$ Our main result is that all the newly detected phenomena linked to money creation are connected to the presence of risks and bank default. In the absence of idiosyncratic and aggregate risks, the loanable-funds approach and the money-creation approaches are equivalent, since the allocations are identical.

In this paper, we rely on an important line of reasoning which shows that fiat money can have positive value in a finite-horizon model when, first, there are sufficiently large penalties when debts to governments—-such as tax liabilities-are not paid, and, second, there are sufficiently large gains from using and trading

\footnotetext{
3 The issues related to the money-creation approach have a long history. The contributions by Tobin (1963) and Gurley and Shaw (1960) are renowned. In particular, Tobin (1963) verbally identifies potential economic limits to the amount of money the private banking sector can create.

4 The loanable-funds version of the model is inspired by earlier general equilibrium approaches to banking such as Gersbach (2013) and Gersbach et al. (2015).

5 As we will discuss, default can occur out-of-equilibrium. Nevertheless, we deliberately avoid all intricate issues of default in equilibrium with banks, an area that has been significantly developed in a series of papers, such as, for instance, Espinoza et al. (2009), Lin et al. (2016) and Martinez and Tsomocos (2018).
} 
money. ${ }^{6}$ To this literature we add the two-tier structure with privately and publicly created monies. Commercial banks create bank deposits (privately created money) when they grant loans to firms enabling them to buy investment goods. Bank deposits will be used later by households to buy consumption goods. ${ }^{7}$ The central bank creates reserves (publicly created money) when it grants loans to commercial banks, enabling them to settle claims on privately created money among banks. The publicly created money is often called "central bank money". The essential assumption for a positive value of fiat money in our paper is that banks (the shareholders) face large penalties if they default against the central bank, and thus banks will never choose to default. An explicit deposit-in-advance constraint is not needed.

\subsection{Structure of the paper}

The paper is organized as follows: Sect. 2 gives an overview of the two models. Their common features are detailed in Sect. 3. Section 4 describes and analyzes the loanable-funds model, and Sect. 5 describes and analyzes the money-creation model. Section 7 concludes.

\section{Overview}

We first describe the common set-up of the two models in Sect. 2.1 and then set out their particularities in Sect. 2.2 for the so-called "loanable-funds model" and in Sect. 2.3 for the so-called "money-creation model."

\subsection{Common set-up}

We build a general equilibrium model with two periods $(t=0,1)$, one physical good, and two production sectors. Households are initially endowed with the good and own the firms in the two production sectors. In period $t=0$, households consume a part of the good, and the rest is invested in the production in both sectors. At the start of period $t=1$, production takes place in both sectors. At the end of period $t=1$, households consume the amount of produced goods.

After the initial consumption of a share of the physical good at the beginning of the first period $(t=0)$, households found and fund banks by exchanging equity contracts against some amount of physical good in the loanable-funds model and by

\footnotetext{
6 See for example Shubik and Wilson (1977), Dubey and Geanakoplos (1992), Dubey and Geanakoplos (2003a, 2003b), Shapley and Shubik (1977), and Kiyotaki and Moore (2003). There are various important approaches to constructing general equilibrium models with money to which we cannot do justice in this paper. We refer to Huber et al. (2014) for a summary of the reasons why the value of fiat money can be positive in finite and infinite horizon models and for Shubik and Tsomocos (1992) for a model with a mutual bank and fractional reserves.

7 For simplicity, we will neglect payments via banknotes and thus, all consumption goods will be bought via bank deposits. Therefore, this setting is equivalent to a model with a deposit-in-advance constraint. Such constraints - usually in the form of cash-in-advance constraints-have been introduced by Clower (1967) and Lucas (1982). For a discussion of their foundations, see Shi (2002).
} 
exchanging equity contracts against money in the money-creation model. In one sector, firms are plagued by moral hazard, but banks, acting as delegated monitors, can alleviate moral hazard problems. These firms thus can only be financed by bank loans. The other sector can be directly financed by households, who provide the firms with the remaining amount of the physical good in exchange for bonds. These bonds represent the agreement that firms will deliver some amount of the physical good after production in the second period $(t=1)$ against the provision of some amount of the physical good in the first period. In the second period, firms and banks pay dividends from profits to households, who are their shareholders.

Although there is no risk in the production technologies and default will not occur in equilibrium, it is nevertheless necessary to account carefully for default risk of banks out-of-equilibrium, in particular in the money creation model. ${ }^{8}$ Government authorities fully insure the households' deposits. ${ }^{9}$ Banks defaulting against households are bailed out, and government authorities finance the bail-out with lump-sum taxation.

\subsection{Loanable-funds model}

In period $t=0$, households consume a part of their endowment of the physical good. They also found and fund banks by providing them with some amount of the physical good in exchange for deposits and equity contracts. Banks then lend this amount of the physical good to firms in one sector which are plagued by moral hazard. The other sector is directly financed by households, who provide firms in this sector with the remaining amount of the physical good. In period $t=1$, firms in the bank-financed sector repay the loans in terms of the physical good, which enables banks to repay depositors and shareholders. All contracts and all variables are denominated in terms of the physical good, and no money is involved.

\subsection{Money-creation model}

In period $t=0$, households consume part of their endowment of the physical good. The firms in one sector are financed by bank loans. Money in the form of bank deposits is created at the same time as loans are granted to these firms. The bank deposits serve as a store of value and as a means of payment. Households sell part of the physical good that was not consumed in period $t=0$ to the latter firms in exchange for deposits, which enable households to invest in bank equity and bank deposits. The other sector is directly financed by households, who provide firms in this sector with the remaining amount of the physical good in exchange for bonds.

The banks that experience an inflow of deposits from other banks that is lower than outflow have a net liability against other banks. Banks that have net liabilities against other banks can repay their liability by borrowing from the central bank

\footnotetext{
${ }^{8}$ Default could occur, for instance, if the central bank policy rate (and as consequence the deposit rate) is above the loan interest rate and a bank creates more deposits than the average bank.

9 Insurance of deposits but not of bank equity precludes the latter from serving as a medium of exchange in the money creation model.
} 
electronic central bank money at the policy rate and by paying with it. Electronic central bank money-or simply reserves-will thus be transferred to the banks that have claims against other banks, and the central bank will pay some interest according to the policy rate. We note that the presence of the central bank and the use of reserves to settle interbank liabilities are essential for the working of the monetary architecture. Otherwise, deposits could not serve as a medium of exchange.

In period $t=1$, anticipating the repayment of the firms financed by banks, nondefaulting banks pay dividends to their shareholders in the form of deposits. Households use these deposits to buy the amount of the physical good produced by the firms. Bank loans are repaid by these firms with their deposits. When borrowers pay loans back, the deposits originally created during period $t=0$ are destroyed. At the end of period $t=1$, by the repayment of loans, both types of money-central bank money and private deposits-are destroyed.

\section{Common features of the two models}

Sections 3.1 to 3.4 present the features common to both models. In Sect. 3, we do not use bold characters to distinguish between variables denominated in real terms and variables denominated in nominal terms. The difference will be spelled out in each of Sects. 3.1 to 3.4 , if necessary.

\subsection{Entrepreneurs}

Firms employ two different technologies that use an amount of a physical good in period $t=0$ to produce some amount of the physical good in the next period. Entrepreneurs operate these firms and maximize shareholder value.

There is a moral hazard technology called "MT." Entrepreneurs running the firms using $\mathrm{MT}^{10}$ are subject to moral hazard. That is, their pledgeable revenues, i.e. the revenues an entrepreneur can credibly promise to pay to external financiers, are low. In particular, they are lower than the repayment obligations they would face in the bond market (see Holmström and Tirole (1997) for the foundations of limited pledgeability). Banks act as delegated monitors and alleviate the moral hazard problem. For simplicity, we assume that banks can completely eliminate the moral hazard problem, i.e. that they can ensure the repayment of loans or the liquidation value if the latter is smaller. ${ }^{11} \mathrm{We}$ also assume that monitoring costs are zero. ${ }^{12}$

We use $K_{M} \in[0, W]$ to denote the aggregate amount of the physical good invested in MT in period $t=0$, where $W>0$ denotes the total amount of the physical good in the economy in period $t=0$. We use $f_{M}\left(K_{M}\right)$ to denote the amount of the physical good produced by MT in period $t=1$. In the loanable-funds model, $R_{L}>0$ denotes the real gross rate of return, which is the amount of the physical

\footnotetext{
${ }^{10}$ The firms using MT constitute a so-called "Sector MT".

11 Typically, MT is used by small or opaque firms that cannot obtain direct financing. Banks monitor them, for instance, by inspecting their business operations and cash flows, and by requiring collateral.

${ }^{12}$ Adding the same monitoring costs for the loanable-funds and money-creation model does not affect our results.
} 
good to be repaid by firms in period $t=1$ for the use of one unit of physical good in period $t=0$. In the money-creation model, it denotes the nominal gross rate of return, which is the amount of money to be repaid by firms in period $t=1$ for the use of one unit of nominal investment in period $t=0$.

There is a frictionless technology referred to as "FT". Entrepreneurs running the firms using $\mathrm{FT}^{13}$ are not subject to any moral hazard problem. ${ }^{14}$ We use $K_{F} \in[0, W]$ to denote the aggregate amount of the physical good invested in FT in period $t=0$, which is also equal to the amount of bonds $S_{F}=K_{F}$ issued by firms using FT to finance the investment $K_{F}$. We also use $f_{F}\left(K_{F}\right)$ to denote the amount of the physical good produced by FT in period $t=1$ and $R_{F}$ to denote the amount of the physical good to be repaid by firms using FT in period $t=1$ for the use of one unit of physical good in period $t=0$.

We assume two technologies in the model to study the mix of bank and bond financing and to examine whether the loanable funds and the money creation approach yield different financing mixes. We assume twice continuously differentiable production functions and: ${ }^{15}$

\section{Assumption 1}

$$
f_{F}^{\prime}, f_{M}^{\prime}>0 \text { and } f_{F}^{\prime \prime}, f_{M}^{\prime \prime}<0, f_{F}^{\prime}(0)=f_{M}^{\prime}(0)=\infty
$$

This assumption ensures that total production cannot be maximized by allocating the entire amount of the physical good to one sector of production only. We assume pricetaking firms in each sector, run by entrepreneurs and assume a representative firm in each sector. Firms using MT and FT are owned by households, and as long as the firms' profits, denoted by $\Pi_{M}$ and $\Pi_{F}$ respectively, are positive, they are paid to owners as dividends. The shareholder values are given by $\max \left(\Pi_{M}, 0\right)$ and $\max \left(\Pi_{F}, 0\right)$, respectively. ${ }^{16}$

\subsection{Banks}

In Sect. 3.2, all variables except the one that denotes a bank are denominated in real terms in the loanable-funds model and in nominal terms in the money-creation model.

There is a set of banks of measure 1 , which we label $b \in[0,1]$. Banks are perfectly competitive, i.e., they take interest rates as given. Bankers that operate these banks maximize shareholder value. Banks offer equity and deposit contracts and grant loans to the firms using MT. Individual amounts are denoted by $e_{B}, d_{H}$ and $l_{m}$, respectively, and may be further indexed by a specific bank $b$, if necessary. Aggregate quantities are denoted by capital letters $E_{B}, D_{H}$ and $L_{m}$, respectively. We denote the lending gross rate of such loans by $R_{L}$. As discussed above, we assume

\footnotetext{
13 The firms using FT constitute a so-called "Sector FT."

14 Typically, these entrepreneurs run well-established firms that need no monitoring.

15 For a function $g$ not defined in 0 , but for which the limit in 0 exists, we use the notation $g(0)=\lim _{x \rightarrow 0} g(x)$.

16 The profits and the shareholder values are denominated in real terms in the loanable-funds model and in nominal terms in the money-creation model.
} 
that banks can perfectly alleviate the moral hazard problem when investing in MT by monitoring borrowers and enforcing contractual obligations. Moreover, monitoring costs are assumed to be zero.

An identical amount of equity financing $e_{B}$ is invested in each bank. As the set of banks is of measure 1, the individual amount $e_{B}$ is identical to the aggregate amount $E_{B}$. We assume $E_{B}>0$ and thus we have circumstances in which banks are founded and funded ${ }^{17}$ and can engage in lending activities. Limited liability protects bank owners, and Bank $b$ pays dividends as long as profits denoted by $\Pi_{B}^{b}$ are positive. The gross rate of return on equity and the bank shareholders' value are given by $R_{E}^{b}=\frac{\max \left(\Pi_{B}^{b}, 0\right)}{e_{B}}$ and $\max \left(\Pi_{B}^{b}, 0\right)$, respectively.

We assume that households keep their deposits $D_{H}$ evenly distributed across all banks at all times: $d_{H}=D_{H}$. For example, they never transfer deposits from their account at one bank to another bank. The deposit gross rate is denoted by $R_{D}$.

\subsection{Households}

There is a continuum of identical households of measure 1 and thus we can focus on a representative household initially endowed with $W$ units of a physical good and ownership of all firms in the economy. In period $t=0$, households consume a part of the physical good and invest or sell the rest of it. The amount of the physical good consumed by the representative household in period $t=0$ is denoted by $C_{0}$, and the remaining amount of the physical good invested by the representative household in period $t=0$ is denoted by $I=W-C_{0}$. Households' portfolio decision-making involves investment in bank deposits, bank equity, and bonds issued by firms using FT. ${ }^{18}$ Households are also paid some dividends from firm ownership. Households consume the entire physical good produced in period $t=1$, and we denote the representative household's consumption by $C_{1}$ in period $t=1$.

We use $u(\cdot)$ to denote the representative household's utility function for consumption in a given period and $\delta(0<\delta \leq 1)$ to denote the households' time discount factor. The household's total intertemporal utility, which we denote by $U\left(C_{0}, C_{1}\right)$, is then given by

$$
U\left(C_{0}, C_{1}\right):=u\left(C_{0}\right)+\delta u\left(C_{1}\right) .
$$

We assume that the utility function is twice continuously differentiable, with $u^{\prime}>0$, $u^{\prime \prime}<0$, as well as the following Inada condition:

$$
u^{\prime}(0)=\infty
$$

In words, the above assumption ensures that a household's consumption cannot be maximized either by the consumption or by the investment of the entire amount of the physical good in period $t=0$.

\footnotetext{
17 In practice, some minimal equity has to be invested in a bank to apply for a banking license.

18 Alternatively, we could assume that firms using FT are only financed by equity. Since firms using FT are financed only by direct frictionless investment from households, they do not have any preference between the various possible capital structures, and our results are not affected by this assumption.
} 


\subsection{Government authorities}

Banks that default on households' deposits are bailed out by government authorities, which finance this bail-out by levying lump-sum taxes on all households. As a result, deposits are a safe investment. In practice, the use of deposits as a means of payment requires them to be safe.

\section{Loanable-funds model}

We outline the sequence of events in Sect. 4.1. In Sect. 4.2, we define and characterize equilibria with banks, and we investigate their welfare properties and implications.

\subsection{Timeline of events}

\subsubsection{Period $t=0$}

Households start with endowment W (equal to their equity) and first consume some amount of their physical good and then found and fund banks by providing them with an amount of physical good $K_{M}$ in exchange for deposits $D_{H}$ and equity contracts $E_{B} \cdot{ }^{19}$ Banks lend the physical good $K_{M}=L_{M}$ to firms using MT. They will repay the loans in the next period in terms of the physical good. Firms in the other sector are directly financed by households providing the firms with the remaining amount $K_{F}$ of the physical good in exchange for bonds $S_{F}$. These bonds represent the agreement that firms will deliver some amount of the physical good after production in the second period against the provision of one unit of the physical good in the first period.

The households' and the banks' balance sheets at the end of period $t=0$ are shown in Table 1.

$E_{H}$ denotes the households' equity. At the end of period $t=0$, household equity is simply equal to the amount of the physical good invested in bonds, bank deposits, and bank equity. Hence, $E_{H}=W-C_{0}$. In period $t=1$, the households' equity evolves depending on the returns on these investments and the profits of firms in both sectors of production. ${ }^{20}$ We thus obtain the bank's profits as follows:

$$
\begin{aligned}
\Pi_{B} & =l_{M} R_{L}-d_{H} R_{D} \\
& =l_{M}\left(R_{L}-R_{D}\right)+e_{B} R_{D} .
\end{aligned}
$$

The interactions between agents during the first period are illustrated in Fig. 1.

\footnotetext{
19 In the loanable-funds model, gross rates of return and all other variables are measured in terms of the physical good.

${ }^{20}$ Note that firms in both sectors are also owned by households, which may receive dividends from profits.
} 
Table 1 Balance sheets at the end of period $t=0$ in the loanable-funds model

\begin{tabular}{|c|c|}
\hline \multicolumn{2}{|c|}{ Households } \\
\hline$S_{F}$ & \\
$D_{H}$ & $E_{H}$ \\
$E_{B}$ & \\
\hline
\end{tabular}

\begin{tabular}{|l|l|}
\hline \multicolumn{2}{|c|}{ Bank $b$} \\
\hline$l_{M}$ & $d_{H}$ \\
& $e_{B}$ \\
\hline
\end{tabular}

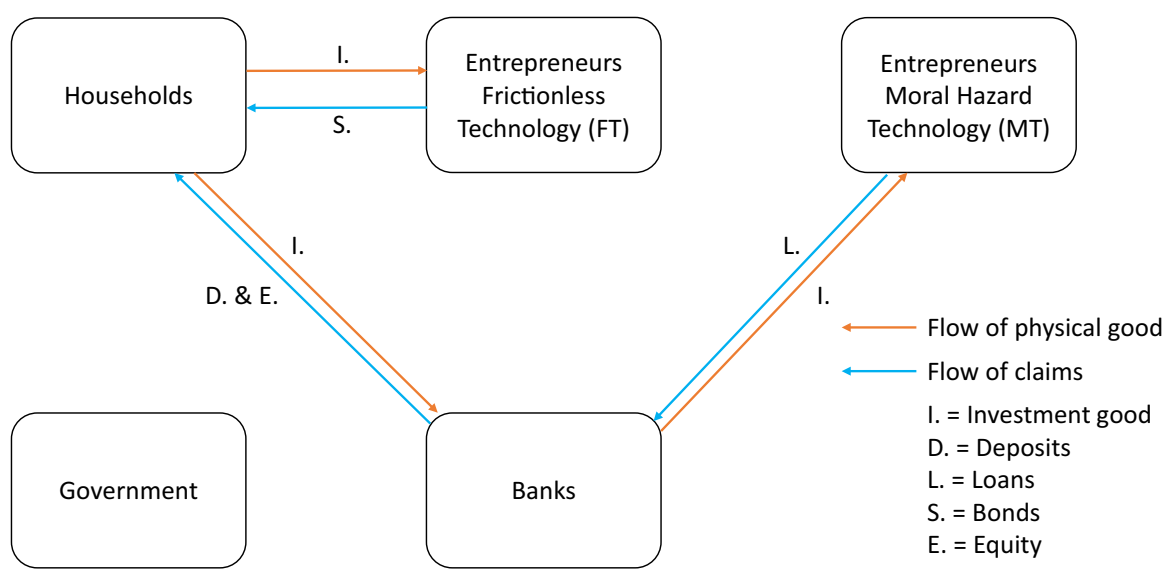

Fig. 1 Flows between agents in period $t=0$

\subsubsection{Period $t=1$}

Entrepreneurs in MT produce $f_{M}\left(K_{M}\right)$ units of the physical good and use this output to repay the loans $L_{M} R_{L}$ to banks. Then banks that do not default against households repay them with $D_{H} R_{D}$ and pay dividends $E_{B} R_{E}$. Banks that default against households receive from them some taxes $T$. The lump-sum taxes the households have to pay are assumed to be considered an exogenous variable by households, who believe that they cannot influence the size of the lump-sum taxes by their actions. The bail-out makes it possible to pay the depositors $D_{H} R_{D}$ in all circumstances. Entrepreneurs in FT produce $f_{F}\left(K_{F}\right)$ units of the physical good and repay households $K_{F} R_{F}$ for the use of $K_{F}$ units of the physical good in period $t=0$. Finally, the entrepreneurs in both sectors pay dividends to their shareholders.

Figure 2 summarizes the agents' interactions in period $t=1$.

\subsection{Equilibria with banks}

\subsubsection{Definition}

We define an equilibrium with banks as follows: 


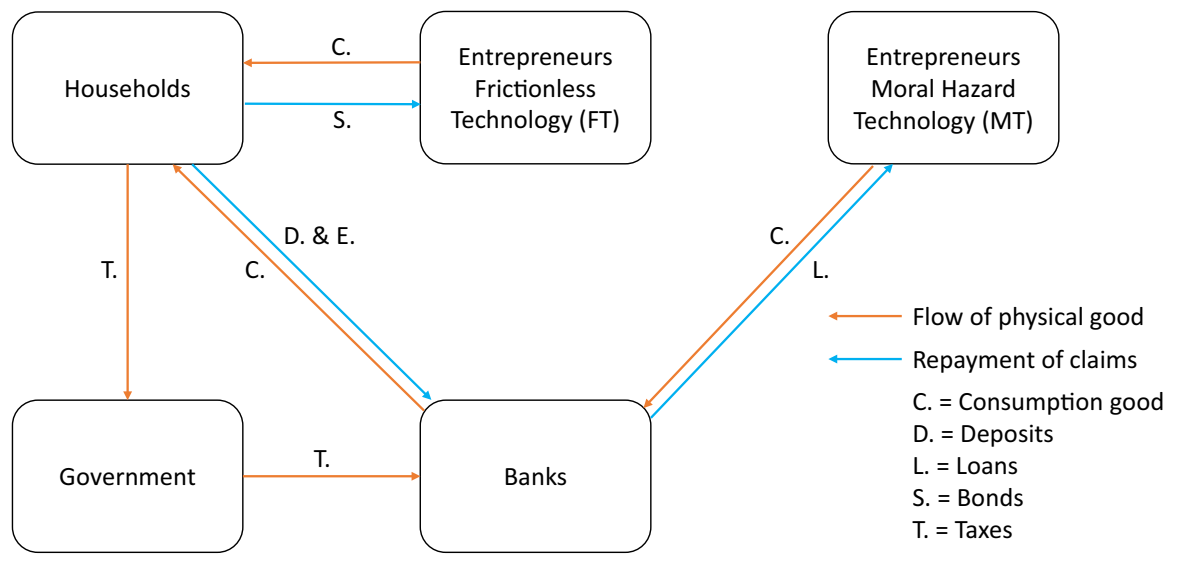

Fig. 2 Flows between agents in period $t=1$

Definition 1 An equilibrium with banks in the sequential market process described in Sect. 4.1 with no bank default is defined as a tuple

$$
\begin{aligned}
& \left(R_{E}, R_{D}, R_{L}, R_{F},\right. \\
& E_{B}, D_{H}, L_{M}, S_{F}, \\
& \left.K_{M}, K_{F}\right),
\end{aligned}
$$

such that

- households hold some private deposits $D_{H}>0$ in period $t=0$,

- banks are founded and funded and receive a positive amount of equity $E_{B}>0$,

- households maximize their utility

$$
\begin{array}{ll}
\max _{D_{H}, E_{B}, S_{F}, I \in[0, W]}\left\{u\left(C_{0}\right)+\delta u\left(C_{1}\right)\right\} \\
\text { s.t. } \quad\left\{\begin{array}{ll}
C_{0}= & W-I, \\
C_{1}= & E_{B} R_{E}+D_{H} R_{D}+f_{F}\left(S_{F}\right)+f_{M}\left(E_{B}+D_{H}\right)-\left(E_{B}+D_{H}\right) R_{L},
\end{array} \text { and } \quad E_{B}+D_{H}+S_{F}=I,\right.
\end{array}
$$

taking gross rates of return $R_{E}, R_{D}$, and $R_{L}$ as given, and

- entrepreneurs in MT and FT maximize their shareholder value, given respectively by

$$
\begin{gathered}
\max _{K_{M} \in[0, I]}\left\{\max \left(f_{M}\left(K_{M}\right)-K_{M} R_{L}, 0\right)\right\}, \\
\max _{K_{F} \in[0, I]}\left\{\max \left(f_{F}\left(K_{F}\right)-K_{F} R_{F}, 0\right)\right\},
\end{gathered}
$$

taking gross rates of return $R_{L}$ and $R_{F}$ as well as investment $I$ as given. 
Henceforth, the superscript ${ }^{*}$ will be used to denote variables in equilibrium. We first characterize the optimum investment allocation. The social planner's problem in the frictionless economy is given by

$$
\begin{array}{ll} 
& \max _{\left\{K_{M}, K_{F}, I\right\}} u(W-I)+\delta u\left(f_{M}\left(K_{M}\right)+f_{F}\left(K_{F}\right)\right), \\
\text { s.t. } \quad & \left\{\begin{array}{l}
0 \leq I \leq W, \\
0 \leq K_{F} \leq I, \\
0 \leq K_{M} \leq I,
\end{array} \text { and } I=K_{M}+K_{F} .\right.
\end{array}
$$

We obtain

Proposition 1 There exists a unique optimal allocation $\left(I, K_{M}, K_{F}\right)$ with $I \in(0, W)$ and $K_{F}, K_{M} \in(0, I)$ which is defined by the following system of equations:

$$
\left\{\begin{array}{ccc}
u^{\prime}(W-I) & = & \delta u^{\prime}\left(f_{M}\left(I-K_{F}\right)+f_{F}\left(K_{F}\right)\right) f_{M}^{\prime}\left(I-K_{F}\right), \\
f_{F}^{\prime}\left(K_{F}\right) & = & f_{M}^{\prime}\left(I-K_{F}\right) \\
I & = & K_{F}+K_{M} .
\end{array}\right.
$$

The proof of Proposition 1 is given in Appendix 4. We denote the first-best levels of $K_{F}, K_{M}$, and $I$ by $K_{F}^{F B}, K_{M}^{F B}$, and $I^{F B}$, respectively.

\subsubsection{Individually optimal choices}

We next examine equilibria with banks. Banks passively lend the amount of the physical good with which the households have provided them to firms using MT. ${ }^{21}$ Regarding the households' investment behavior, we can characterize the representative household's optimal portfolio choice as follows:

Lemma 1 Suppose that there is no bank default. Then, the representative household's portfolio choice $\left(E_{B}, D_{H}, S_{F}, I\right)$ involves $0<I<W$, and with $E_{B}>0, D_{H}>0$ it is optimal if

$$
\begin{aligned}
\delta f_{F}^{\prime}\left(S_{F}^{*}(I)\right) u^{\prime} & \left(\left(I-S_{F}^{*}(I)-D_{H}\right)\left(R_{E}-R_{L}\right)\right. \\
& \left.+D_{H}\left(R_{D}-R_{L}\right)+f_{F}\left(S_{F}^{*}(I)\right)+f_{M}\left(I-S_{F}^{*}(I)\right)\right)=u^{\prime}(W-I),
\end{aligned}
$$

where $S_{F}^{*}(I)$ is the unique solution to

$$
R_{E}-R_{L}+f_{M}^{\prime}\left(I-S_{F}\right)=f_{F}^{\prime}\left(S_{F}\right)
$$

and $D_{H}$ has to fulfill

$$
\begin{aligned}
\left(R_{E}-R_{L}+f_{M}^{\prime}\left(D_{H}\right)\right) \delta u^{\prime}\left(D_{H}\left(R_{D}-R_{L}\right)\right. & \left.+f_{F}\left(S_{F}^{*}(I)\right)+f_{M}\left(D_{H}\right)\right) \\
& >u^{\prime}\left(W-S_{F}^{*}(I)-D_{H}\right),
\end{aligned}
$$

and $R_{E}=R_{D}$. Reciprocally, such tuples constitute the representative household's optimal portfolio choices.

\footnotetext{
${ }^{21}$ In equilibrium, banks cannot do better by investing in the bond market.
} 
The proof of Lemma 1 is given in Appendix 4. We now turn to the firms' behavior.

Lemma 2 Demands for the physical good by firms using MT and FT are represented by two real-valued functions denoted by $\hat{K}_{M}: \mathbb{R}_{+} \times[0, W] \rightarrow[0, I]$ and $\hat{K}_{F}: \mathbb{R}_{+} \times[0, W] \rightarrow[0, I]$, respectively and given by

$$
\begin{aligned}
\hat{K}_{M}\left(R_{L}, I\right) & =\left\{\begin{array}{c}
I \leq \quad \text { if } \quad R_{L} \leq f_{M}^{\prime}(I), \\
f_{M}^{\prime-1}\left(R_{L}\right) \leq \quad \\
\text { otherwise. }
\end{array}\right. \\
\leq \text { and } \quad \hat{K}_{F}\left(R_{F}, I\right) & =\left\{\begin{array}{cc}
I \leq & \text { if } \quad R_{F} \leq f_{F}^{\prime}(I), \\
f_{F}^{\prime-1}\left(R_{F}\right) \leq & \text { otherwise. }
\end{array}\right.
\end{aligned}
$$

The proof of Lemma 2 is given in Appendix 4.

\subsubsection{Characterization}

The preceding lemmata enable us to characterize all equilibria with banks. For this, we use the notation $\varphi=\frac{E_{B}}{L_{M}}$ to denote the aggregate equity ratio of the banking system. We obtain

Theorem 1 All equilibria with banks take the following form:

$$
\begin{gathered}
R_{E}^{*}=R_{D}^{*}=R_{L}^{*}=R_{F}^{*}=f_{F}^{\prime}\left(K_{F}^{F B}\right), \\
E_{B}^{*}=\varphi^{*}\left(I^{F B}-K_{F}^{F B}\right), \quad D_{H}^{*}=\left(1-\varphi^{*}\right)\left(I^{F B}-K_{F}^{F B}\right), \\
L_{M}^{*}=\left(I^{F B}-K_{F}^{F B}\right), \quad S_{F}^{*}=K_{F}^{F B}, \\
K_{M}^{*}=I^{F B}-K_{F}^{F B}, \quad K_{F}^{*}=K_{F}^{F B},
\end{gathered}
$$

where the aggregate equity ratio $\varphi^{*} \in(0,1)$ is arbitrary. Equilibrium profits of firms and banks are given by

$$
\begin{gathered}
\Pi_{M}^{*}=f_{M}\left(I^{F B}-K_{F}^{F B}\right)-\left(I^{F B}-K_{F}^{F B}\right) f_{F}^{\prime}\left(K_{F}^{F B}\right), \\
\Pi_{F}^{*}=f_{F}\left(K_{F}^{F B}\right)-K_{F}^{F B} f_{F}^{\prime}\left(K_{F}^{F B}\right), \\
\Pi_{B}^{*}=\varphi^{*}\left(I^{F B}-K_{F}^{F B}\right) f_{F}^{\prime}\left(K_{F}^{F B}\right) .
\end{gathered}
$$

The proof of Theorem 1 is given in Appendix 4 . 


\subsubsection{Welfare properties and implications}

Theorem 1 directly implies

Corollary 1 The first-best allocation is implemented in any equilibrium with banks.

The capital structure of banks is indeterminate within the set of equilibria with banks, which are given in Theorem 1. This is a macroeconomic illustration of the Modigliani-Miller Theorem. As the gross rates of return on deposits and equity are equal and no equilibrium with banks involves any banks' default, households do not have any preference between various possible capital structures. We obtain

Corollary 2 Given some aggregate equity ratio $\varphi^{*} \in(0,1)$, all equilibrium values with banks are uniquely determined.

\section{Money-creation model}

We first describe the institutional set-up in Sect. 5.1. Then we outline the detailed sequence of events in Sect. 5.2. Finally, in Sect. 5.3 we define and characterize equilibria with banks and investigate their welfare properties and implications. To help the reader to differentiate between nominal and real variables, subsequently we will use bold characters to denote the latter.

\subsection{Institutional set-up}

We impose favorable conditions on the functioning of the monetary architecture and the public authorities.

\subsubsection{Interbank market and monies}

In our current monetary architecture, there are two forms of money (public and private monies) and three types of money creation. ${ }^{22}$ The central bank, which we also call "CB," creates the first form of money when it grants loans to banks. This money is a claim of banks against the central bank and it is publicly created. We call it "CB deposits." Commercial banks create the second form of money when they grant loans to firms or other banks. This money is a claim of households, firms, or banks against other banks. It is privately created by banks and destroyed when bank equity is bought and loans are repaid. We call it "private deposits."

We now discuss the principles that connect the two forms of money. When private deposits are used in monetary transactions, these deposits are transferred from the buyer's bank, say $b_{j}$, to the seller's bank, say $b_{i}$. The settlement of this transaction requires Bank $b_{j}$ to become liable to $b_{i}$. There are now two options for these banks. Either Bank $b_{j}$ applies for a loan from the CB and pays Bank $b_{i}$ with

\footnotetext{
${ }^{22}$ We do not consider coins and banknotes as the third type of money, as agents would not use them in the absence of transaction costs associated with the use of bank deposits. Deposits are used in all monetary transactions.
} 
$\mathrm{CB}$ deposits, or it directly obtains a loan from Bank $b_{i}$. The institutional rule is that one unit of CB money settles one unit of liabilities of privately created money and that both types of money have the same unit. This sets the "exchange rate" between $\mathrm{CB}$ money and privately created money at $1 .^{23}$ Finally, we do not consider transaction costs for using $\mathrm{CB}$ or private deposits in monetary transactions.

We use $p_{I}$ and $p_{C}$ to denote the price of the physical good in period $t=0$ and $t=1$ in units of both publicly created and privately created monies, respectively. To differentiate nominal from real variables-i.e. variables denominated in terms of the physical good-, we express the latter in bold characters.

We integrate an interbank market. The same gross rate is applied to loans and deposits for borrowing and depositing among banks. Deposits owned by other banks and deposits owned by households cannot be discriminated. As a result, the gross rate on the interbank market is equal to the deposit gross rate paid to households, and we denote this gross rate by $R_{D}$. The interbank market works as follows: At any time, banks can reimburse their debt against the CB by paying with their deposits at other banks, they can reimburse their interbank liabilities by paying with $\mathrm{CB}$ deposits, and they can require their debtor banks to reimburse their interbank liabilities in terms of $\mathrm{CB}$ deposits. ${ }^{24}$ Accordingly, as long as banks can refinance themselves at the $\mathrm{CB}$, interbank borrowing is not associated with default risk. Finally, we assume the following tie-breaking rule to simplify the analysis: If banks are indifferent between participating in the interbank market and transacting with the $\mathrm{CB}$, they will choose the latter.

\subsubsection{Role of public authorities}

Two public authorities - a CB and a government-ensure the functioning of the monetary architecture. These authorities fulfill three roles. First, banks can obtain loans from the $\mathrm{CB}$ and can thus acquire $\mathrm{CB}$ deposits at the same policy gross rate $R_{C B}$ at any stage of economic activities where $R_{C B}-1$ is the $\mathrm{CB}$ interest rate. This assumption implies that the exact flow of funds at any particular stage is irrelevant for banks' decisions, as interest payments to or from the CB depend only on their net position at the end of the first period. ${ }^{25}$ Second, government authorities levy very large penalties on the bankers who let their bank default on liabilities to any public authority. ${ }^{26}$ As a result, banks will avoid defaulting on their obligations to the $\mathrm{CB}$ at all costs. Third, we assume that the CB buys interbank loans that cannot be repaid by the counterparty bank. By this mechanism, no bank defaults on interbank loans, as the very large penalties for defaulting against the $\mathrm{CB}$ translate into very large penalties for defaulting against other banks.

\footnotetext{
23 In principle, this exchange rate could be set at any other level.

24 The interbank market is examined in detail in Appendix 3. To ensure that only equilibria with $R_{D}=$ $\mathrm{R}_{\mathrm{CB}}$ can arise we assume for simplicity that no bank taking part in the interbank market suffers any loss by doing so.

25 Note that this assumption also prevents bank runs.

26 As banks can obtain loans from the $\mathrm{CB}$ at any time, very large penalties for defaulting against the CB would be sufficient.
} 
We explore equilibrium outcomes for different $\mathrm{CB}$ policy gross rates and we determine the associated level of welfare expressed in terms of household consumption. We assume that the CB aims at maximizing the welfare of households.

\subsection{Timeline of events}

In the following, we describe the sequence of events in more detail. To that end, we split each period into stages. Figure 3 illustrates the timeline of events.

\subsubsection{Period $t=0$}

\section{Stage A: Banks are founded.}

There are two cases. When no bank is founded because bank equity is not a profitable investment for households, there is a unique possible allocation of the physical good, which can be found in Sect. 5.2.2. In the other case, households promise to turn a predefined share $\varphi \in(0,1]$ of their deposits into bank equity $E_{B}=\varphi D_{M}$ before production in stage C. In the latter case, shareholder value per unit of equity is the gross rate of return on equity, and we denote it by $R_{E}^{b}=\frac{\max \left(\Pi_{B}^{b}, 0\right)}{e_{B}}$. In the rest of Sect. 5.2, we concentrate on the case where households found and fund banks, unless we specify otherwise.

\section{Stage B: Loans are granted to firms and money is created by banks.}

Bank $b$ grants loans $l_{M}^{b}$ to firms using MT at the lending gross rate $R_{L} \cdot d_{M}^{b}$ deposits at Bank $b$ and the corresponding aggregate deposits $D_{M}=L_{M}$ are simultaneously created in this process. The ratio of lending by a single Bank $b$ to the average lending by all banks can be expressed as $\alpha_{M}^{b}:=\frac{l_{M}^{b}}{L_{M}}{ }^{27}$ MT firms' deposits are spread across banks according to $d_{M}^{b}$ (or $\alpha_{M}^{b}$ ).

\section{Stage C: Firms in MT purchase the physical good and households invest in} bank equity and firms in FT.

Households sell a part of their endowment of the physical good to firms using MT against bank deposits. They also buy $S_{F}$ bonds at the real gross rate of return $\mathbf{R}_{\mathbf{F}}$. These bonds are denominated in real terms, which means that one bond exchanges the delivery of $\mathbf{R}_{\mathbf{F}}$ units of the physical good in the second period against one unit of the physical good in the first period. ${ }^{28}$ Households consume the rest of their endowment. At the end of the first period, households use part of their deposits to buy the equity $E_{B}$ that they promised in stage A. The purchase of bank equity destroys this part of deposits in the economy. We denote the individual amount of deposits after the purchase of bank equity by $d_{H}$, and we denote the resulting aggregate amount of deposits by $D_{H}=L_{M}-E_{B}$. At the end of the first period and depending on the amount of loans they have granted, some banks labeled $b_{j}$ have

\footnotetext{
27 As banks constitute a set of measure equal to one, the average lending per bank is equal to aggregate lending $L_{M}$, and the ratio of individual to average lending is given by $\alpha_{M}^{b}$.

28 In practice, such bonds are called "inflation-indexed bonds." Our results stay qualitatively similar with bonds denominated in nominal terms. However, such a change renders the analysis significantly more complicated, as it adds the constraint that firms using FT do not default.
} 


\begin{tabular}{|c|c|c|c|c|}
\hline \multicolumn{3}{|c|}{$t=0$} & \multicolumn{2}{|c|}{$t=1$} \\
\hline Stage A & Stage B & Stage $\mathrm{C}$ & Stage D & Stage E \\
\hline $\begin{array}{c}\text { Banks are } \\
\text { founded }\end{array}$ & $\begin{array}{l}\text { Loans are } \\
\text { granted } \\
\text { to firms } \\
\text { and money } \\
\text { is created } \\
\text { by banks }\end{array}$ & $\begin{array}{l}\text { Firms in MT } \\
\text { purchase } \\
\text { the physical good, } \\
\text { households } \\
\text { invest in } \\
\text { bank equity } \\
\text { and firms in FT } \\
\text { and consume }\end{array}$ & $\begin{array}{l}\text { Firms produce } \\
\text { and the } \\
\text { government } \\
\text { taxes } \\
\text { households }\end{array}$ & $\begin{array}{c}\text { Dividends } \\
\text { are paid, } \\
\text { all debt } \\
\text { is reimbursed, } \\
\text { and households } \\
\text { consume }\end{array}$ \\
\hline
\end{tabular}

Fig. 3 Timeline of events

Table 2 End of stage C: Banks' and households' balance sheets

\begin{tabular}{|c|c|}
\hline \multicolumn{2}{|c|}{ Households } \\
\hline$S_{F}$ & \\
$D_{H}$ & $E_{H}$ \\
$E_{B}$ & \\
\hline
\end{tabular}
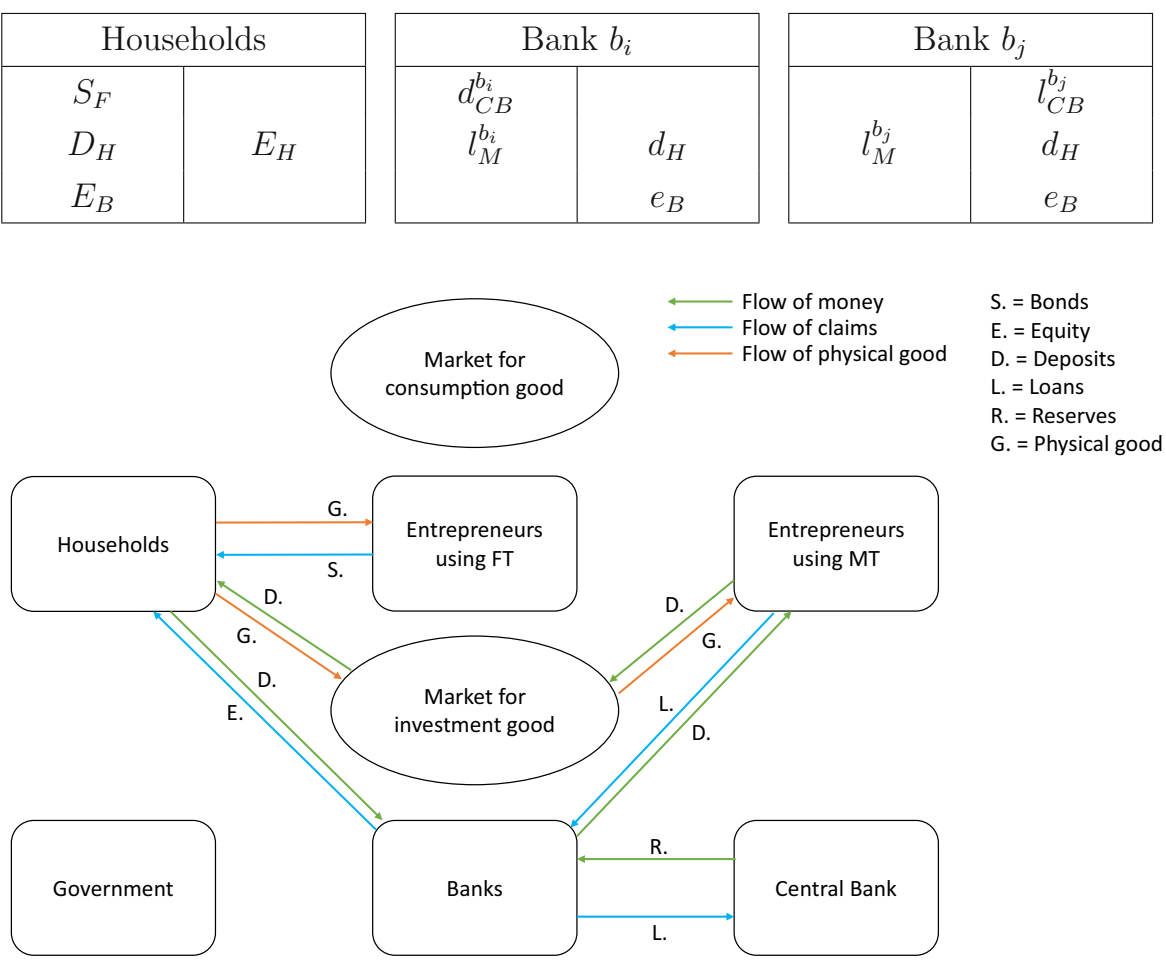

Fig. 4 Flows between agents in period $t=0$

liabilities $l_{C B}^{b_{j}}$, and the other banks $b_{i}$ have claims $d_{C B}^{b_{i}}$ against the CB. These processes are detailed in Appendix 1. The balance sheets are shown in Table 2, with $E_{H}$ denoting total households ownership.

The interactions between agents during the first period are illustrated in Fig. 4. 


\subsubsection{Period $\mathrm{t}=1$}

In the second period, Bank $b$ 's profits ${ }^{29}$ can be derived from the bank balance sheets given in Table 2 and using Equation (18) in Appendix 1 and Appendix 2:

$$
\begin{aligned}
\Pi_{B}^{b} & =\left(1-\alpha_{M}^{b}\right) L_{M} R_{C B}+\alpha_{M}^{b} L_{M} R_{L}-d_{H} R_{D} \\
& =\left(1-\alpha_{M}^{b}\right) L_{M} R_{C B}+\alpha_{M}^{b} L_{M} R_{L}-\left(L_{M}-E_{B}\right) R_{D} \\
& =\alpha_{M}^{b} L_{M}\left(R_{L}-R_{C B}\right)+L_{M}\left(R_{C B}-R_{D}\right)+E_{B} R_{D} .
\end{aligned}
$$

Equation (9) holds for any bank, independently of whether it has deposits or liabilities at the central bank. As banks maximize their profits when choosing the level of lending determined by $\alpha_{M}^{b}$, they will never default in any possible set of variables. We thus do not consider the case where banks default. The following description can be divided into two cases: Either no bank is founded, or some banks are founded and funded.

\section{Case I: Banks are not founded.}

In this case, $E_{B}=0$. This case represents an equilibrium. Such an equilibrium is called an "equilibrium without banks." In such a situation, no money is created, and investment in MT is not possible. The physical good is thus entirely invested into Sector FT: ${ }^{30}$

$$
\mathbf{K}_{\mathbf{M}}^{*}=\mathbf{0} \quad \text { and } \quad \mathbf{K}_{\mathbf{F}}^{*}=\mathbf{W},
$$

where ${ }^{*}$ denotes equilibrium variables. This is an inefficient allocation, as Assumption 1 implies that it is socially desirable to invest a positive amount in MT.

\section{Case II: Banks are founded.}

Then the following stages occur:

\section{Stage D: Firms produce and the government taxes households.}

Firms produce in both sectors and repayments fall due. Profits from firms are given by

$$
\begin{aligned}
\Pi_{M} & =\mathbf{f}_{\mathbf{M}}\left(\mathbf{K}_{\mathbf{M}}\right) p_{C}-\mathbf{K}_{\mathbf{M}} R_{L} p_{I}, \\
\Pi_{\mathbf{F}} & =\mathbf{f}_{\mathbf{F}}\left(\mathbf{K}_{\mathbf{F}}\right)-\mathbf{K}_{\mathbf{F}} \mathbf{R}_{\mathbf{F}} .
\end{aligned}
$$

The balance sheets are given in Table 3 , where $R_{H}$ denotes the resulting gross rate of return on household ownership of the physical goods and of both production technologies.

\section{Stage E: Dividends are paid and all debt is reimbursed and households consume.}

Dividends from bank equity are distributed to shareholders. Households purchase the physical good for consumption. Debts are reimbursed. Appendix 2 details these

\footnotetext{
29 Note that because we have assumed that no bank defaults in equilibrium, profits will be non-negative. If Bank $b$ defaulted, $\Pi_{B}^{b}$ would take negative values. However, in this latter case, the value to shareholders would be equal to zero. The shareholders are protected by limited liability, so they will not be affected by losses $\Pi_{B}^{b}$.

${ }^{30}$ Note that the purchase of the output from Sector FT does not require any bank deposit, as bonds are denominated in real terms and are reimbursed in terms of the physical good.
} 
Table 3 End of stage D, no bank defaults: Banks' and households' balance sheets

\begin{tabular}{|c|c|}
\hline \multicolumn{2}{|c|}{ Households } \\
\hline$S_{F} \mathbf{R}_{\mathbf{F}}$ & $E_{H} R_{H}$ \\
$D_{H} R_{D}$ & \\
$E_{B} R_{E}$ & \\
$\Pi_{\mathbf{F}}$ & \\
$\Pi_{M}$ & \\
\hline
\end{tabular}

\begin{tabular}{|c|c|}
\hline \multicolumn{2}{|c|}{ Bank $b_{i}$} \\
\hline$d_{C B}^{b_{i}} R_{C B}$ & \\
$l_{M}^{b_{i}} R_{L}$ & $d_{H} R_{D}$ \\
& $e_{B} R_{E}^{b_{i}}$ \\
\hline
\end{tabular}

\begin{tabular}{|l|c|}
\hline \multicolumn{2}{|c|}{ Bank $b_{j}$} \\
\hline & $l_{C B}^{b_{j}} R_{C B}$ \\
$l_{M}^{b_{j}} R_{L}$ & $d_{H} R_{D}$ \\
& $e_{B} R_{E}^{b_{j}}$ \\
\hline
\end{tabular}

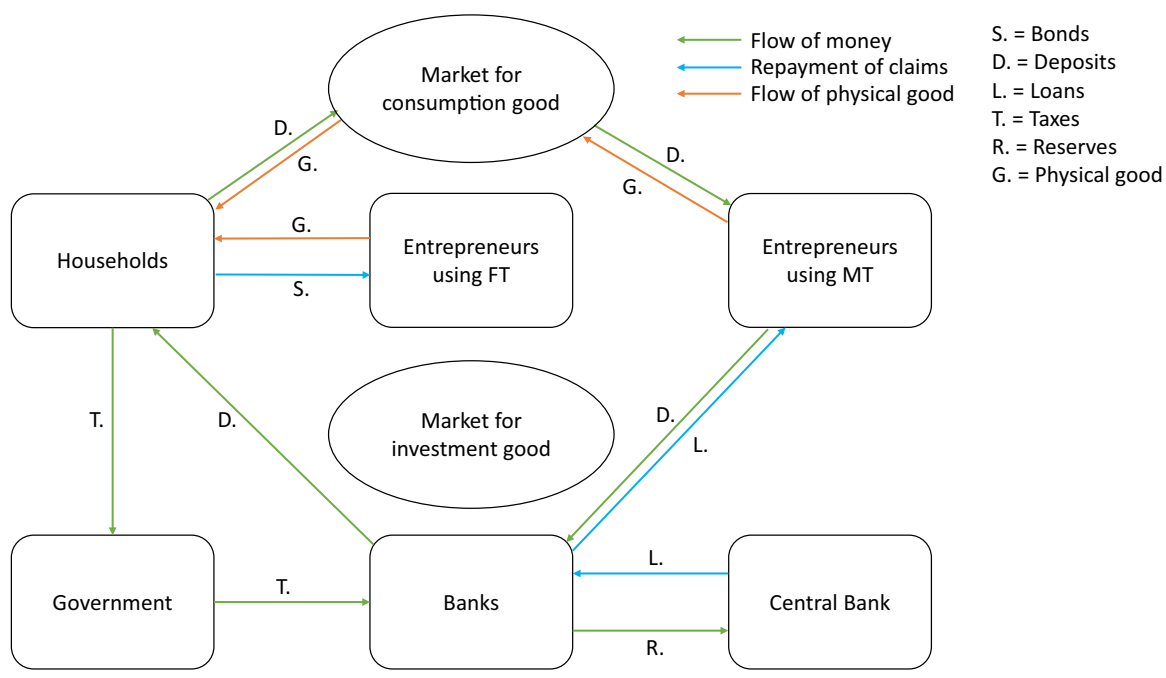

Fig. 5 Flows between agents in period $t=1$

processes. The banks' balance sheets have empty balances, and households end up with all the consumption goods produced, $\mathbf{f}_{\mathbf{M}}\left(\mathbf{K}_{\mathbf{M}}\right)+\mathbf{f}_{\mathbf{F}}\left(\mathbf{K}_{\mathbf{F}}\right)$.

The interactions between agents during the second period are illustrated in Fig. 5.

\subsection{Equilibria with banks}

\subsubsection{Definition}

The details of the sequential market process are given in Sect. 5.2. We only consider symmetric equilibria with banks in this setting, i.e. equilibria with banks in which all of them choose the same amount of lending and money creation. These banks thus have identical balance sheets in equilibrium. Moreover, the policy gross rate $R_{C B}$ is set by the $\mathrm{CB}$, so that equilibria with banks are dependent on this choice.

Definition 2 We assume that the central bank sets the policy gross rate $R_{C B}$. The setting is given by the sequential market process in Sect. 5.2. We define a symmetric equilibrium with banks in this setting as a tuple 


$$
\begin{aligned}
\mathcal{E}:= & \left(\mathbf{K}_{\mathbf{M}}, \mathbf{K}_{\mathbf{F}},\right. \\
& E_{B}, D_{H}, L_{M}, S_{F}, \\
& \left.R_{E}, R_{D}, R_{L}, \mathbf{R}_{\mathbf{F}}, p_{I}, p_{C}\right)
\end{aligned}
$$

consisting of physical investment allocations, savings, and finite and positive gross rates of return and prices, such that

- some private deposits $D_{H}>0$ are held by households at the end of stage C,

- households maximize their utility

$$
\begin{aligned}
& \max _{\left\{D_{H}, E_{B}, S_{F}, \mathbf{I} \in[\mathbf{0}, \mathbf{W}]\right\}}\left\{u\left(\mathbf{C}_{\mathbf{0}}\right)+\delta u\left(\mathbf{C}_{\mathbf{1}}\right)\right\} \\
& \text { s.t. }\left\{\begin{aligned}
\mathbf{C}_{\mathbf{0}}= & \mathbf{W}-\mathbf{I}, \\
\mathbf{C}_{\mathbf{1}}= & \frac{E_{B} R_{E}+D_{H} R_{D}-\left(E_{B}+D_{H}\right) R_{L}}{p_{C}} \\
& +\mathbf{f}_{\mathbf{F}}\left(S_{F}\right)+\mathbf{f}_{\mathbf{M}}\left(\frac{E_{B}+D_{H}}{p_{I}}\right),
\end{aligned}\right. \\
& \text { and } E_{B}+D_{H}+p_{I} S_{F}=p_{I} \mathbf{I},
\end{aligned}
$$

taking prices $p_{I}$ and $p_{C}$ as well as gross rates of return $R_{E}, R_{D}$, and $R_{L}$ as given, - each bank $b \in[0,1]$ and all firms maximize their shareholder value, ${ }^{31}$ given respectively by

$$
\begin{aligned}
& \max _{\mathbf{K}_{\mathbf{M}} \in[\mathbf{0}, \mathbf{W}]}\left\{\max \left(\mathbf{f}_{\mathbf{M}}\left(\mathbf{K}_{\mathbf{M}}\right) p_{C}-\mathbf{K}_{\mathbf{M}} R_{L} p_{I}, 0\right)\right\}, \\
& \max _{\mathbf{K}_{\mathbf{F}} \in[\mathbf{0}, \mathbf{W}]}\left\{\max \left(\mathbf{f}_{\mathbf{F}}\left(\mathbf{K}_{\mathbf{F}}\right)-\mathbf{K}_{\mathbf{F}} \mathbf{R}_{\mathbf{F}}, 0\right)\right\}, \\
& \text { and } \max _{\alpha_{M}^{b} \geq 0}\left\{\max \left(\alpha_{M}^{b} L_{M}\left(R_{L}-R_{C B}\right)+L_{M}\left(R_{C B}-R_{D}\right)+E_{B} R_{D}, 0\right)\right\} \text {, }
\end{aligned}
$$

taking prices $p_{I}$ and $p_{C}$ as well as gross rates of return $R_{D}, R_{L}$, and $\mathbf{R}_{\mathbf{F}}$ as given,

- the same level of money creation is chosen by all banks, and

- markets for the physical good clear in both periods.

In the remainder of the paper, we only consider symmetric equilibria with banks. However, we may omit the word "symmetric" for ease of presentation. We can write the social planner's problem as follows:

$$
\begin{array}{ll} 
& \max _{\left\{\mathbf{K}_{\mathbf{M}}, \mathbf{K}_{\mathbf{F}}, \mathbf{I}\right\}} u(\mathbf{W}-\mathbf{I})+\delta u\left(\mathbf{f}_{\mathbf{M}}\left(\mathbf{K}_{\mathbf{M}}\right)+\mathbf{f}_{\mathbf{F}}\left(\mathbf{K}_{\mathbf{F}}\right)\right) \\
\text { s.t. } \quad & \left\{\begin{array}{c}
0 \leq \mathbf{I} \leq \mathbf{W}, \\
0 \leq \mathbf{K}_{\mathbf{F}} \leq \mathbf{I}, \quad \text { and } \quad \mathbf{I}=\mathbf{K}_{\mathbf{M}}+\mathbf{K}_{\mathbf{F}} . \\
0 \leq \mathbf{K}_{\mathbf{M}} \leq \mathbf{I},
\end{array}\right.
\end{array}
$$

\footnotetext{
31 In our model, there is an equivalence between the maximization of profits in nominal terms by firms and by banks and the maximization of profits in real terms. Details are available on request.
} 
We obtain

Proposition 2 There exists a unique optimal allocation of the social planner's problem $\left(\mathbf{I}, \mathbf{K}_{\mathbf{M}}, \mathbf{K}_{\mathbf{F}}\right)$ with $\mathbf{I} \in(\mathbf{0}, \mathbf{W})$ and $\mathbf{K}_{\mathbf{F}}, \mathbf{K}_{\mathbf{M}} \in(\mathbf{0}, \mathbf{I})$, which is defined by the following system of equations:

$$
\left\{\begin{array}{ccc}
u^{\prime}(\mathbf{W}-\mathbf{I}) & = & \delta u^{\prime}\left(\mathbf{f}_{\mathbf{M}}\left(\mathbf{I}-\mathbf{K}_{\mathbf{F}}\right)+\mathbf{f}_{\mathbf{F}}\left(\mathbf{K}_{\mathbf{F}}\right)\right) \mathbf{f}^{\prime}{ }_{\mathbf{M}}\left(\mathbf{I}-\mathbf{K}_{\mathbf{F}}\right) \\
\mathbf{f}_{\mathbf{F}}^{\prime}\left(\mathbf{K}_{\mathbf{F}}\right) & = & \mathbf{f}_{\mathbf{M}}^{\prime}\left(\mathbf{I}-\mathbf{K}_{\mathbf{F}}\right) \\
\mathbf{I} & = & \mathbf{K}_{\mathbf{F}}+\mathbf{K}_{\mathbf{M}}
\end{array}\right.
$$

The proof of Proposition 2 is identical to that of Proposition 1, which is given in Appendix 4. We denote the first-best levels of $\mathbf{K}_{\mathbf{F}}, \mathbf{K}_{\mathbf{M}}$, and $\mathbf{I}$ by $\mathbf{K}_{\mathbf{F}}^{\mathbf{F B}}, \mathbf{K}_{\mathbf{M}}^{\mathbf{F B}}$, and $\mathbf{I}^{\mathbf{F B}}$, respectively.

\subsubsection{Individually optimal choices}

In this section, we determine the optimal strategies of banks, households, and firms. We first establish the way in which the deposit gross rate is related to the policy gross rate. The absence of arbitrage opportunities on the interbank market in any equilibrium with banks implies

Lemma 3 The nominal gross rate on the interbank market is equal to

$$
R_{D}^{*}=R_{C B}
$$

in any equilibrium with banks.

The proof of Lemma 3 is given in Appendix 4. It uses the absence of arbitrage opportunities on the interbank market in any equilibrium with banks. Banks could exploit any differential in the gross rates by lending or borrowing on the interbank market to increase their shareholder value.

We next examine the amount of money created by an individual bank. Whenever there is no finite optimum amount of money creation, we denote the banks' strategy by " $\infty$." We thus obtain

Proposition 3 We assume that $R_{D}=R_{C B}$. Then, we denote by ${ }^{32} \hat{\alpha}_{M}: \mathbb{R}_{++}^{2} \rightarrow$ $\mathcal{P}(\mathbb{R} \cup\{+\infty\})$ the sets of individually optimum amounts of lending and money creation by a single bank. This correspondence is given by

$$
\hat{\alpha}_{M}\left(R_{L}, R_{C B}\right)=\left\{\begin{array}{cc}
\{+\infty\} & \text { if } R_{L}>R_{C B} \\
{[0,+\infty)} & \text { if } R_{L}=R_{C B} \\
\{0\} & \text { if } R_{L}<R_{C B}
\end{array}\right.
$$

\footnotetext{
${ }^{32}$ For all sets denoted by $X$, we denote the power set of $X$ by $\mathcal{P}(X)$.
} 
The proof of Proposition 3 is given in Appendix 4. The banks' behavior only depends on $R_{L}-R_{C B}$, which is the intermediation margin. If the intermediation margin is zero, it is obvious that banks are indifferent between all lending levels. For positive intermediation margins, banks would like to grant as many loans as possible. When the intermediation margin is negative, banks will choose not to grant any loan. In the following, we describe the representative household's portfolio choice:

Lemma 4 The representative household's portfolio choice $\left(E_{B}, D_{H}, S_{F}, \mathbf{I}\right)$ is optimal for all $\mathbf{I}>\mathbf{0}$ such that

$$
\begin{aligned}
\delta \mathbf{f}^{\prime}{ }_{\mathbf{F}}\left(S_{F}^{*}(\mathbf{I})\right) u^{\prime}( & \left(p_{I} \mathbf{I}-p_{I} S_{F}^{*}(\mathbf{I})-D_{H}\right) \frac{R_{E}-R_{L}}{p_{C}} \\
& \left.+D_{H} \frac{R_{D}-R_{L}}{p_{C}}+\mathbf{f}_{\mathbf{F}}\left(S_{F}^{*}(\mathbf{I})\right)+\mathbf{f}_{\mathbf{M}}\left(\mathbf{I}-S_{F}^{*}(\mathbf{I})\right)\right)=u^{\prime}(\mathbf{W}-\mathbf{I}),
\end{aligned}
$$

where $S_{F}^{*}(\mathbf{I})$ is the unique solution to

$$
p_{I} \frac{R_{E}-R_{L}}{p_{C}}+\mathbf{f}^{\prime}{ }_{\mathbf{M}}\left(\mathbf{I}-S_{F}\right)=\mathbf{f}_{\mathbf{F}}^{\prime}\left(S_{F}\right)
$$

and $D_{H}$ is small enough such that

$$
\begin{aligned}
& \left(p_{I} \frac{R_{E}-R_{L}}{p_{C}}+\mathbf{f}^{\prime}{ }_{\mathbf{M}}\left(\frac{D_{H}}{p_{I}}\right)\right) \delta u^{\prime}\left(D_{H} \frac{R_{D}-R_{L}}{p_{C}}+\mathbf{f}_{\mathbf{F}}\left(S_{F}^{*}(\mathbf{I})\right)+\mathbf{f}_{\mathbf{M}}\left(\frac{D_{H}}{p_{I}}\right)\right) \\
& >u^{\prime}\left(\mathbf{W}-S_{F}^{*}(\mathbf{I})-\frac{D_{H}}{p_{I}}\right) \text {. }
\end{aligned}
$$

In addition, $R_{E}=R_{D}$ has to hold. Reciprocally, such tuples constitute the representative household's optimum portfolio choices.

The proof of Lemma 4 is similar to that of Lemma 1, which is given in Appendix 4. We now turn to firms' behavior.

Lemma 5 Demands for the physical good by firms using MT and FT are represented by two real functions denoted by $\hat{\mathbf{K}}_{\mathbf{M}}: \mathbb{R}_{+} \times[\mathbf{0}, \mathbf{W}] \rightarrow[\mathbf{0}, \mathbf{I}]$ and $\hat{\mathbf{K}}_{\mathbf{F}}: \mathbb{R}_{+} \times[\mathbf{0}, \mathbf{W}] \rightarrow[\mathbf{0}, \mathbf{I}]$, respectively and given by

$$
\begin{aligned}
& \hat{\mathbf{K}}_{\mathbf{M}}\left(R_{L}, \mathbf{I}\right)=\left\{\begin{array}{cl}
\mathbf{I} & \text { if } \frac{R_{L}}{p_{C}} p_{I} \leq \mathbf{f}^{\prime}{ }_{\mathbf{M}}(\mathbf{I}), \\
f_{M}^{\prime-1}\left(\frac{R_{L}}{p_{C}} p_{I}\right) & \text { otherwise. }
\end{array}\right. \\
& \text { and } \quad \hat{\mathbf{K}}_{\mathbf{F}}\left(\mathbf{R}_{\mathbf{F}}, \mathbf{I}\right)=\left\{\begin{array}{cl}
\mathbf{I} & \text { if } \quad \mathbf{R}_{\mathbf{F}} \leq \mathbf{f}_{\mathbf{F}}^{\prime}(\mathbf{I}), \\
\mathbf{f}_{\mathbf{F}}^{\prime-1}\left(\mathbf{R}_{\mathbf{F}}\right) & \text { otherwise. }
\end{array}\right.
\end{aligned}
$$


The proof of Lemma 5 is similar to that of Lemma 2, which is given in Appendix 4.

\subsubsection{Characterization}

The preceding lemmata enable us to characterize all equilibria with banks.

Theorem 2 Given some $C B$ policy gross rate $R_{C B}$, all equilibria with banks take the following form:

$$
\begin{gathered}
R_{E}^{*}=R_{D}^{*}=R_{L}^{*}=R_{C B}=p_{C}^{*} \frac{\mathbf{R}_{\mathbf{F}}^{*}}{p_{I}^{*}}=p_{C}^{*} \frac{\mathrm{f}_{\mathrm{F}}^{\prime}\left(\mathbf{K}_{\mathbf{F}}^{\mathbf{F B}}\right)}{p_{I}^{*}}, \\
E_{B}^{*}=\varphi^{*}\left(\mathbf{I}^{\mathbf{F B}}-\mathbf{K}_{\mathbf{F}}^{\mathbf{F B}}\right), \quad D_{H}^{*}=\left(1-\varphi^{*}\right)\left(\mathbf{I}^{\mathbf{F B}}-\mathbf{K}_{\mathbf{F}}^{\mathbf{F B}}\right), \\
L_{M}^{*}=\left(\mathbf{I}^{\mathbf{F B}}-\mathbf{K}_{\mathbf{F}}^{\mathbf{F B}}\right), \quad S_{F}^{*}=\mathbf{K}_{\mathbf{F}}^{\mathbf{F B}}, \\
\mathbf{K}_{\mathbf{M}}^{*}=\mathbf{I}^{\mathbf{F B}}-\mathbf{K}_{\mathbf{F}}^{\mathbf{F B}}, \quad \mathbf{K}_{\mathbf{F}}^{*}=\mathbf{K}_{\mathbf{F}}^{\mathbf{F B}},
\end{gathered}
$$

where the aggregate equity ratio $\varphi^{*} \in(0,1)$ and $p_{I}^{*}>0$ are arbitrary. Equilibrium profits of firms and banks are given by

$$
\begin{gathered}
\Pi_{M}^{*}=p_{C}^{*}\left(\mathbf{f}_{\mathbf{M}}\left(\mathbf{I}^{\mathbf{F B}}-\mathbf{K}_{\mathbf{F}}^{\mathbf{F B}}\right)-\left(\mathbf{I}^{\mathbf{F B}}-\mathbf{K}_{\mathbf{F}}^{\mathbf{F B}}\right) \mathbf{f}_{\mathbf{F}}^{\prime}\left(\mathbf{K}_{\mathbf{F}}^{\mathbf{F B}}\right)\right), \\
\Pi_{F}^{*}=\mathbf{f}_{\mathbf{F}}\left(\mathbf{K}_{\mathbf{F}}^{\mathbf{F B}}\right)-\mathbf{K}_{\mathbf{F}}^{\mathbf{F B}} \mathbf{f}_{\mathbf{F}}^{\prime}\left(\mathbf{K}_{\mathbf{F}}^{\mathbf{F B}}\right) \\
\Pi_{B}^{*}=\varphi^{*} p_{C}^{*}\left(\mathbf{I}^{\mathbf{F B}}-\mathbf{K}_{\mathbf{F}}^{\mathbf{F B}}\right) \mathbf{f}_{\mathbf{F}}^{\prime}\left(\mathbf{K}_{\mathbf{F}}^{\mathbf{F B}}\right) .
\end{gathered}
$$

The proof of Theorem 2 is similar to that of Theorem 1, which is given in Appendix 4. We now make the following observations.

First, we examine the equilibrium conditions in detail. All nominal gross rates are equal to the policy gross rate set by the $\mathrm{CB}$, as expressed in (11). There is a unique equilibrium with banks in real terms, i.e. with respect to the physical allocation to both sectors, which is shown in (14), and thus with regard to the real values of saving and lending in (13), where $L_{M}^{*}$ is divided by $p_{I}^{*}$. Equations (15), (16), and (17) represent the profits of firms and banks. Firms' dividends from Sector FT are distributed in the form of the physical good, while banks and firms in Sector MT distribute dividends in the form of deposits.

Second, the system is indeterminate with regard to the price of the physical good in period $t=0$ and the capital structure. This has two implications. The economic system is nominally anchored by the price of the physical good in $t=0$ and the CB interest rate, which determine prices and interest rates, and the banks' capital ratio determines the asset structure and the payment processes.

Third, the theorem implies that there are no incentives for banks to create more private money. The creation of money by a bank above the average level of money created would require the bank to borrow from the central bank at the gross rate 
$R_{C B}$, as the deposits created in excess of the average level of money would flow to other banks. Since all nominal gross rates are equal to the policy gross rates, this additional money creation is not profitable.

Fourth, the physical investment allocation does not depend on the capital structure, so bank equity capital does not need to be regulated. Fifth, the physical investment allocation is independent of the CB policy gross rate. Monetary policy is neutral. Sixth, in an equilibrium with banks, all banks create the same amount of money and, after the payment processes in stage $C$ in period $t=0$ (see Figure 3), end up with the same amount of household deposits. Hence, in equilibrium, no interbank liabilities emerge and banks do not need to borrow central bank money from the $\mathrm{CB}$ to settle interbank liabilities. Hence, positive nominal interest rates are sustained in equilibrium since the banking system as a whole does not incur repayment obligations in $t=0$ against the central bank and thus does not need to pay these obligations back later, plus interest.

The conclusion also holds out of equilibrium. If an individual bank creates more private money than another bank through higher loan financing, it ends up with higher deposit outflows than the other banks, and thus has to borrow reserves from the central bank to settle interbank liabilities. However, the other banks obtain the additional amount of reserves and the banking system as a whole has again no liabilities against the central bank.

Hence, also in such cases out of equilibrium, the banking system does not need any further means at the end of the lifetime. Banks that have initially received reserves will obtain interests on their deposits at the $\mathrm{CB}$, but need these reserves to settle the higher outflow of deposits and end up with zero central bank reserves. Banks who have initially borrowed reserves are charged with interest rates on these liabilities, but will receive exactly the same amount of reserves when higher loan repayments lead to less outflow of deposits.

Finally, we note that the money market clears as follows. Whenever banks have decided to create a certain amount of money and the central bank has set its nominal interest rate $R_{C B}$, prices for investment goods and all other interest rates adjust, such that the money market and commodity markets clear.

In the next subsection, we investigate the welfare properties of the equilibria with banks found in Theorem 2, and we compare them with the ones found for the loanable-funds model in Theorem 1.

\subsubsection{Welfare properties and implications}

The equilibria with banks described in Theorem 2 are indeterminate in two respects, (a) with regard to the price of the physical good in period $t=0$ and $(b)$ with regard to the capital structure of banks. In the former case, we simply have a price normalization problem, and we can set $p_{I}=1$ without loss of generality. The indifference between various potential capital structures is a macroeconomic illustration of the Modigliani-Miller Theorem. As the gross rates of return on deposits and equity are equal and no equilibrium with banks involves any banks' default, households do not have any preference between various possible capital 
structures. Moreover, the specific capital structure of banks has no impact on money creation and lending by banks. We thus immediately obtain

Corollary 3 Given $p_{I}=1$ and some $\varphi^{*} \in(0,1)$, all equilibrium values are uniquely determined when the $C B$ sets the policy gross rate $R_{C B}$.

Finally, we can compare the equilibria with banks in the loanable-funds model given in Theorem 1 and the equilibria in the money-creation model given in Theorem 2. We obtain

Theorem 3 The investment and consumption allocation in any equilibrium with banks in the loanable-funds model is the same as the one in any equilibrium with banks in the money-creation model. This allocation is first-best.

\section{Extensions and discussions}

So far, we have focused on the equivalence between the loanable-funds and the money-creation model. We next explore extensions and several critical issues of our model and the results.

\subsection{Extensions}

Of course, there are various possibilities for extending the benchmark, such as infinite horizon set-ups and growth processes. As long as there is no uncertainty and thus no bank default, the logic set out in this paper regarding the equivalence of the loanable-funds and money-creation approaches can be expected to hold in these macroeconomic environments.

More subtle extensions concern the following scenario. There is aggregate productivity risk, e.g. production functions are of the types $\tilde{\eta} f_{F}\left(K_{F}\right)$ and $\tilde{\eta} f_{M}\left(K_{M}\right)$, where $\tilde{\eta}$ is a random variable with possible realizations $\eta_{i} \in \mathbb{R}_{+}, i \in\{1, \ldots, n\}$, with $0<\eta_{1}<\cdots<\eta_{n}$. The value $\tilde{\eta}=\eta_{i}$ occurs with probability $p_{\eta_{j}}$, with $\sum_{i=1}^{\eta} p_{\eta_{j}}=1$.

The proof for the equivalence of the loanable-funds approach and the moneycreation approach can be repeated under the following conditions: complete markets, all contracts (loan contracts and deposit contracts) and central bank policy gross rates are made contingent on the state of the world, consumption good markets clear in every state of the world, and all the institutional characteristics-including sufficiently large penalties for defaults against central banks-continue to exist. Then, in such an environment with complete markets and contingent contracts, the equivalence continues to hold, as the proof for the equivalence can be repeated step by step for this environment. However, with aggregate productivity risk, new type of equilibria may emerge. As already shown in Faure and Gersbach (2016) in a much simpler setting, asymmetric equilibria occur in which money creation is different among groups of banks, some banks default and total investments by banks are inefficiently high $^{33}$. Hence, the equivalence between loanable-funds and the

\footnotetext{
${ }^{33}$ This result complements insights from Dubey et al. (2005) with the seminal analysis on default and punishment in general equilibrium.
} 
money-creation model only holds in a restricted sense, i.e., there is an equilibrium in the money-creation model that replicates the investment and consumption allocation in the equilibrium of the loanable-funds model, but the set of equilibria in both models differ.

\subsection{Determination of the price level}

We observe that the equilibrium relationship between nominal and real interest rates and commodity prices today and tomorrow in the money-creation model are governed by the Fisher equation. Indeed, from the equilibrium condition (11), we obtain $1+r=(1+\pi)(1+\mathbf{r})$, where $r\left(=R_{D}^{*}-1\right)$ is the nominal interest rate, $\pi=\frac{p_{c}^{*}}{p_{I}^{*}}-1$ is the inflation rate and $\mathbf{r}=\mathbf{R}_{\mathbf{F}}^{*}-1$ is the real interest rate. As long as $\mathbf{r}$ and $\pi$ are small, we obtain $r \approx \mathbf{r}+\pi$.

In the money-creation model, however, the initial price level is indeterminate and thus the model does not anchor prices. This problem can be resolved by adopting ideas from Dubey and Geanakoplos (1992) and two changes of the model. First, we assume that households start with an endowment of outside money, say $M$, measured in the unit of account. The outside money would typically be banknotes issued by the central bank. Second, banks would be required to hold a fraction of their issued deposits as banknotes at the central bank. If households exchange their outside money at the beginning into bank deposits to earn interests, banks obtain $M$ and can create bank deposits subject to the reserve requirement. This essentially constrains bank deposit creation and anchors the price of the investment good.

In order to make sure that markets clear in period $t=1$, all inside money is destroyed and banknotes stay at the central bank, the easiest way is to require that the reserves in the form of outside money stay at the central bank forever (or banks are taxed by this amount). In addition, there has to be a uniquely determined equilibrium spread between loan and deposit rates such that the repayment obligation of firms is identical to the amount of deposits households have in period $t=1$ to buy consumption goods. ${ }^{34}$

\subsection{Money neutrality}

The equivalence between the loanable funds and the money creation approach implies that money is neutral, i.e. if the banking system creates a higher amount of bank deposits, this has no impact on the investment and consumption allocation. The neutrality of money in our context arises because a higher amount of private deposits created by banks leads to a proportional increase of the price of investment goods and a subsequent proportional increase of consumption goods. The real

\footnotetext{
34 There is a variety of alternative ways that achieve the same objective. For instance, banks could obtain electronic central bank money to satisfy the reserve requirement. Suppose that the interest rate for borrowing electronic money at the central bank is higher than the interest rate for depositing reserves. Then, if the additional banknotes just allow banks to pay back their obligations at the central bank at the end of period $t=1$, we could obtain the same result regarding the investment and consumption allocation.
} 
purchasing power of firms and households remains unaffected. This parallels other money neutrality results. For instance, in economies with a cash-in-advance economy, no uncertainty, no default, and a representative agent, money is neutral, i.e. changing the endowment of money has no impact on commodity allocations (see e.g. Walsh 2017).

In our context, the essential constraint to obtain equilibria in which money has value is that a fraction of firms has to rely on banks. Specifically, banks competitively create money in the form of deposits that allow these firms to buy investment goods. Since bank deposits are interest-bearing, no deposit-in-advance constraint needs to be imposed to obtain the equilibria in which bank deposits are held.

\section{Conclusion}

The purpose of this paper was to establish the equivalence between the loanablefunds approach and the money-creation approach for particular macroeconomic environments. In such environments, it is much easier to use the shortcut loanablefunds approach, and this paper serves as a justification for using this shortcut. A final remark is in order. To model the properties, challenges (see e.g. Gersbach 2021), and implications of changes in our monetary system, the money creation approach is the suitable framework to be used.

\section{Appendix 1: Stage C}

In the following, we describe in detail all processes, including all payments and investments that occur in stage $\mathrm{C}$. For this, we split stage $\mathrm{C}$ into a series of substages and index all variables that change in some substage by an integer starting from 1 .

\section{Stage C, substage 1: Banks' application for loans from the CB}

Banks will need to settle payment transactions. To do so, they have to make sure that they possess enough CB deposits. Bank $b$ thus applies for a loan from the CB. ${ }^{35}$ We assume that Bank $b$ borrows the amount ${ }^{36}$

$$
l_{C B_{1}}^{b}:=l_{M}^{b}=\alpha_{M}^{b} D_{M} .
$$

As a result, bank-specific $\mathrm{CB}$ deposits amounting to $d_{C B_{1}}^{b}:=l_{C B_{1}}^{b}$ as well as an aggregate amount of $\mathrm{CB}$ deposits amounting to $D_{C B_{1}}:=D_{M}>0$ are created. Moreover, we have $D_{M}=L_{M}$. Household and bank balance sheets are given in Table 4, where $E_{H}$ denotes total household ownership.

\footnotetext{
35 Borrowing from, and depositing at, the $\mathrm{CB}$ is formally identical to borrowing from and depositing at other banks through the interbank market. Accordingly, we only describe the situation where all banks exclusively borrow from and deposit at the CB.

36 In this first substage, banks do not need to borrow all that much in order to guarantee payments in subsequent substages, as banks will obtain deposits back from households when firms make payments with their deposits. The amount Bank $b$ needs to borrow from the CB is given by $\max \left(\left(1-\alpha_{M}^{b}\right) L_{M}, 0\right)$. This result is demonstrated in the subsequent substages.
} 
Table 4 End of stage C, substage 1: Bank and household balance sheets

\begin{tabular}{|c|c|}
\hline \multicolumn{2}{|c|}{ Households } \\
\hline $\mathbf{W}$ & $E_{H}$ \\
\hline
\end{tabular}

\begin{tabular}{|c|c|}
\hline \multicolumn{2}{|c|}{ Bank $b$} \\
\hline$d_{C B_{1}}^{b}$ & $l_{C B_{1}}^{b}$ \\
$l_{M}^{b}$ & $d_{M}^{b}$ \\
\hline
\end{tabular}

\section{Stage C, substage 2: purchase of an amount of investment good by firms in MT}

We assume that firms in Sector MT use all their deposits to purchase the largest possible quantity of the physical good that they can afford. As a result, they do not hold deposits in the next stage $\mathrm{D}^{.37}$

$$
\mathbf{K}_{\mathbf{M}}=\frac{L_{M}}{p_{I}} .
$$

The settlement of these payments requires each bank $b$ to pay $d_{M}^{b}=\alpha_{M}^{b} D_{M}$ of CB deposits to other banks. Moreover, all banks obtain the average amount $d_{H_{1}}:=D_{M}$ of CB deposits back from other banks, where we can interpret $D_{M}$ as being the average amount of private deposits created. We note that $d_{H_{1}}$ is homogeneous across banks, which derives from our assumption that deposits are kept evenly distributed by households across all banks at any point in time. The corresponding aggregate amount is denoted by $D_{H_{1}}$ and is equal to $D_{M}$. This transaction affects the CB deposits of Bank $b$ as follows:

$$
d_{C B_{2}}^{b}:=d_{C B_{1}}^{b}-\alpha_{M}^{b} D_{M}+D_{M}=D_{M} .
$$

Household and bank balance sheets are given in Table 5.

\section{Stage $C$, substage 3: investment in FT}

When buying $S_{F}$ bonds from firms using FT, the households deliver $\mathbf{K}_{\mathbf{F}}=S_{F}$ units of the physical good against the promise to obtain $\mathbf{K}_{\mathbf{F}} \mathbf{R}_{\mathbf{F}}$ units of the physical good from FT after production. Household and bank balance sheets are given in Table 6.

\section{Stage C, substage 4: offsetting CB assets against CB liabilities}

Now banks can offset their CB assets against CB liabilities, as they no longer need $\mathrm{CB}$ deposits to settle further payments before production. We use

$$
\delta^{b}:=d_{C B_{2}}^{b}-l_{C B_{1}}^{b}=\left(1-\alpha_{M}^{b}\right) L_{M}
$$

\footnotetext{
${ }^{37}$ Note that this assumption is not essential and that it does not affect the equilibrium allocation of the physical good, as no firm would be able to increase their shareholder value by holding deposits in equilibrium.
} 
Table 5 End of stage C, substage 2: Bank and household balance sheets

\begin{tabular}{|c|c|}
\hline \multicolumn{2}{|c|}{ Households } \\
\hline $\mathbf{K}_{\mathbf{F}}$ & $E_{H}$ \\
$D_{H_{1}}$ & \\
\hline
\end{tabular}

\begin{tabular}{|c|c|}
\hline \multicolumn{2}{|c|}{ Bank $b$} \\
\hline$d_{C B_{2}}^{b}$ & $l_{C B_{1}}^{b}$ \\
$l_{M}^{b}$ & $d_{H_{1}}$ \\
\hline
\end{tabular}

Table 6 End of stage C, substage 3: Bank and household balance sheets

\begin{tabular}{|c|c|}
\hline \multicolumn{2}{|c|}{ Households } \\
\hline$S_{F}$ & $E_{H}$ \\
$D_{H_{1}}$ & \\
\hline
\end{tabular}

\begin{tabular}{|c|c|}
\hline \multicolumn{2}{|c|}{ Bank $b$} \\
\hline$d_{C B_{2}}^{b}$ & $l_{C B_{1}}^{b}$ \\
$l_{M}^{b}$ & $d_{H_{1}}$ \\
\hline
\end{tabular}

Table 7 End of stage C, substage 4: Bank and household balance sheets

\begin{tabular}{|c|c|}
\hline \multicolumn{2}{|c|}{ Households } \\
\hline$S_{F}$ & \\
$D_{H_{1}}$ & $E_{H}$ \\
\hline
\end{tabular}

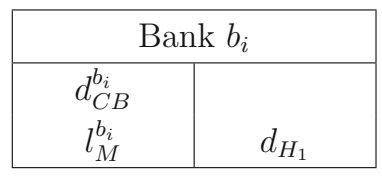

\begin{tabular}{|l|l|}
\hline \multicolumn{2}{|c|}{ Bank $b_{j}$} \\
\hline & $l_{C B}^{b_{j}}$ \\
$l_{M}^{b_{j}}$ & $d_{H_{1}}$ \\
\hline
\end{tabular}

to denote the net position of Bank $b$ against the CB. We distinguish banks with claims against the $\mathrm{CB}$ from banks that are its debtors:

$$
\begin{aligned}
& B_{I}:=\left\{b_{i} \in[0,1]\right. & \text { s.t. } & \left.\delta^{b_{i}} \geq 0\right\} \\
\text { and } & B_{J}:=\left\{b_{j} \in[0,1]\right. & \text { s.t. } & \left.\delta^{b_{j}}<0\right\} .
\end{aligned}
$$

Net claims against the CB are denoted by $d_{C B}^{b_{i}}:=\delta^{b_{i}}$ for all $b_{i} \in B_{I}$ and net liabilities by $l_{C B}^{b_{j}}:=-\delta^{b_{j}}$ for all $b_{j} \in B_{J}$. Household and bank balance sheets are given in Table 7 .

\section{Stage C, substage 5: payment of bank equity}

Next, households pay the equity $E_{B}=\varphi D_{M}>0$ pledged in $t=1$, thereby destroying the corresponding amount of bank deposits. We use $D_{H}=(1-\varphi) D_{M}$ to denote the remaining amount of deposits. Accordingly, $D_{H_{1}}=E_{B}+D_{H}$. In Table 2, we show the balance sheets of two typical banks, a net saver at and a net borrower from the $\mathrm{CB}$. 
Table 8 End of stage E, substage 1: Bank and household balance sheets

\begin{tabular}{|c|c|}
\hline \multicolumn{2}{|c|}{ Households } \\
\hline$S_{F} \mathbf{R}_{\mathbf{F}}$ & $E_{H} R_{H}$ \\
$D_{H} R_{D}$ & \\
$E_{B} R_{E}$ & \\
$\Pi_{\mathbf{F}}$ & \\
$\Pi_{M}$ & \\
\hline
\end{tabular}

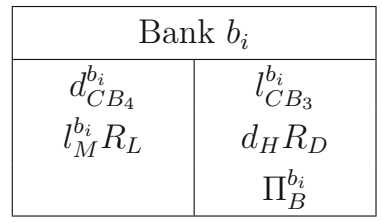

\begin{tabular}{|c|c|}
\hline \multicolumn{2}{|c|}{ Bank $b_{j}$} \\
\hline$d_{C B_{3}}^{b_{j}}$ & $l_{C B_{4}}^{b_{j}}$ \\
$l_{M}^{b_{j}} R_{L}$ & $d_{H} R_{D}$ \\
& $\Pi_{B}^{b_{j}}$ \\
\hline
\end{tabular}

\section{Appendix 2: Stage E-no bank defaults}

In the following, we describe in detail all processes, including all payments and repayments that occur in stage E. For this, we split stage $\mathrm{E}$ into a series of substages, and we index all variables that change in some substage by an integer starting from 1, starting with the last index from Appendix 1.

\section{Stage $E$, substage 1: borrowing of banks from the CB}

To have enough CB deposits to guarantee payments using bank deposits, Bank $b$ borrows the amount $l_{C B_{3}}^{b}=d_{C B_{3}}^{b}:=D_{H} R_{D}+\Pi_{B}^{b}$ from the CB. We use the notations

$$
\begin{aligned}
d_{C B_{4}}^{b_{i}} & :=d_{C B_{3}}^{b_{i}}+d_{C B}^{b_{i}} R_{C B} \\
\text { and } \quad l_{C B_{4}}^{b_{j}} & :=l_{C B_{3}}^{b_{j}}+l_{C B}^{b_{j}} R_{C B} .
\end{aligned}
$$

Household and bank balance sheets are given in Table 8 .

\section{Stage E, substage 2: dividend payment}

Bank profits are paid to households as dividends. This creates bank deposits, and the households' deposits at Bank $b$ become $\tilde{d}_{H}:=D_{H} R_{D}+\Pi_{B}$. The aggregate amount of the households' deposits is then denoted by $\tilde{D}_{H}$. To settle these payments, each bank $b$ transfers $\Pi_{B}^{b}$ to other banks and receives $\Pi_{B}$ from other banks in the form of $\mathrm{CB}$ deposits. These processes affect the $\mathrm{CB}$ deposits of Banks $b_{i}$ and $b_{j}$ as follows:

$$
\text { and } \quad \begin{aligned}
& d_{C B_{5}}^{b_{j}}:=d_{C B_{3}}^{b_{j}}-\Pi_{B}^{b_{j}}+\Pi_{B}=D_{H} R_{D}+\Pi_{B} \\
& d_{C B_{6}}^{b_{i}}:=d_{C B_{4}}^{b_{i}}-\Pi_{B}^{b_{i}}+\Pi_{B}=d_{C B}^{b_{i}} R_{C B}+D_{H} R_{D}+\Pi_{B} .
\end{aligned}
$$

Household and bank balance sheets are given in Table 9. 
Table 9 End of stage E, substage 2: Bank and household balance sheets

\begin{tabular}{|c|c|}
\hline \multicolumn{2}{|c|}{ Households } \\
\hline$S_{F} \mathbf{R}_{\mathbf{F}}$ & $E_{H} R_{H}$ \\
$\tilde{D}_{H}$ & \\
$\Pi_{\mathbf{F}}$ & \\
$\Pi_{M}$ & \\
\hline
\end{tabular}

\begin{tabular}{|c|c|}
\hline \multicolumn{2}{|c|}{ Bank $b_{i}$} \\
\hline$d_{C B_{6}}^{b_{i}}$ & $l_{C B_{3}}^{b_{i}}$ \\
$l_{M}^{b_{i}} R_{L}$ & $\tilde{d}_{H}$ \\
\hline
\end{tabular}

\begin{tabular}{|c|c|}
\hline \multicolumn{2}{|c|}{ Bank $b_{j}$} \\
\hline$d_{C B_{5}}^{b_{j}}$ & $l_{C B_{4}}^{b_{j}}$ \\
$l_{M}^{b_{j}} R_{L}$ & $\tilde{d}_{H}$ \\
\hline
\end{tabular}

Table 10 End of stage E, substage 3: Bank and household balance sheets

\begin{tabular}{|c|c|}
\hline \multicolumn{2}{|c|}{ Households } \\
\hline$\tilde{D}_{H}$ & $E_{H} R_{H}$ \\
$\mathbf{f}_{\mathbf{F}}\left(\mathbf{K}_{\mathbf{F}}\right)$ & \\
\hline
\end{tabular}

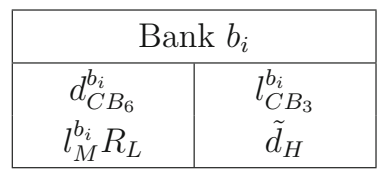

\begin{tabular}{|c|c|}
\hline \multicolumn{2}{|c|}{ Bank $b_{j}$} \\
\hline$d_{C B_{5}}^{b_{j}}$ & $l_{C B_{4}}^{b_{j}}$ \\
$l_{M}^{b_{j}} R_{L}$ & $\tilde{d}_{H}$ \\
\hline
\end{tabular}

\section{Stage E, substage 3: repayment of debt and distribution of profits from firms using FT}

From the repayment of debt $S_{F} \mathbf{R}_{\mathbf{F}}$ and the distribution of profits $\boldsymbol{\Pi}_{\mathbf{F}}$, both in terms of the physical good, households obtain $\mathbf{f}_{\mathbf{F}}\left(\mathbf{K}_{\mathbf{F}}\right)$ units of the physical good. Household and bank balance sheets are given in Table 10 .

\section{Stage E, substage 4: sale of the consumption good produced by MT and distribution of profits from firms using MT}

As firms using MT cannot pay dividends in nominal terms before households buy some amount of the physical good and as households cannot buy the entire amount of the physical good before having received the dividends, we would need to describe cycles where, alternately, firms pay dividends and households buy some amount of the physical good until all dividends are paid and the entire amount of physical good has been bought. To avoid such irrelevant intricacies, we assume that firms using MT pay dividends in real terms.

The firms using MT then sell the remaining amount of the physical good they have produced. Households use their deposits to buy it. ${ }^{38}$ The supply of $\mathbf{f}_{\mathbf{M}}\left(\mathbf{K}_{\mathbf{M}}\right)$ units of the physical good meets the real demand $\frac{\tilde{D}_{H}+\Pi_{M}}{p_{C}}$. Hence, the equilibrium price is given by

$$
p_{C}=\frac{\tilde{D}_{H}+\Pi_{M}}{\mathbf{f}_{\mathbf{M}}\left(\mathbf{K}_{\mathbf{M}}\right)} .
$$

The settlement of these payments requires each bank $b$ to pay $\tilde{d}_{H}$ of $\mathrm{CB}$ deposits to other banks. Moreover, all banks obtain the average amount $d_{M_{1}}^{b}:=\alpha_{M}^{b} \tilde{d}_{H}$ of $\mathrm{CB}$

\footnotetext{
38 Additional deposits are paid to households through banks' dividend payments.
} 
Table 11 End of stage E, substage 4: Bank and household balance sheets

\begin{tabular}{|c|c|}
\hline \multicolumn{2}{|c|}{ Households } \\
\hline $\mathbf{f}_{\mathbf{F}}\left(\mathbf{K}_{\mathbf{F}}\right)$ & $E_{H} R_{H}$ \\
$\mathbf{K}_{\mathbf{M}} \mathbf{R}_{\mathbf{M}}$ & \\
\hline
\end{tabular}

\begin{tabular}{|c|c|}
\hline \multicolumn{2}{|c|}{ Bank $b_{i}$} \\
\hline$d_{C B_{8}}^{b_{i}}$ & $l_{C B_{3}}^{b_{i}}$ \\
$l_{M}^{b_{i}} R_{L}$ & $d_{M_{1}}^{b_{i}}$ \\
\hline
\end{tabular}

\begin{tabular}{|c|c|}
\hline \multicolumn{2}{|c|}{ Bank $b_{j}$} \\
\hline$d_{C B_{7}}^{b_{j}}$ & $l_{C B_{4}}^{b_{j}}$ \\
$l_{M}^{b_{j}} R_{L}$ & $d_{M_{1}}^{b_{j}}$ \\
\hline
\end{tabular}

Table 12 End of stage E, substage 5: Bank and household balance sheets

\begin{tabular}{|c|c|}
\hline \multicolumn{2}{|c|}{ Households } \\
\hline $\mathbf{f}_{\mathbf{F}}\left(\mathbf{K}_{\mathbf{F}}\right)$ & $E_{H} R_{H}$ \\
$\mathbf{K}_{\mathbf{M}} \mathbf{R}_{\mathbf{M}}$ & \\
\hline
\end{tabular}
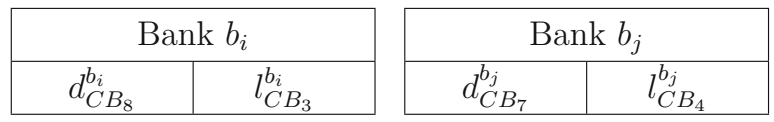

deposits back from other banks. The summation of all banks' profits in Equation (9) implies $L_{M} R_{L}=D_{H} R_{D}+\Pi_{B}$, which yields $d_{M_{1}}^{b}=\alpha_{M}^{b} L_{M} R_{L}$. These transactions affect $\mathrm{CB}$ deposits of Banks $b_{i}$ and $b_{j}$ as follows:

$$
\text { and } \quad \begin{aligned}
d_{C B_{7}}^{b_{j}} & :=d_{C B_{5}}^{b_{j}}-\tilde{d}_{H}+d_{M_{1}}^{b_{j}}=\alpha_{M}^{b_{j}} L_{M} R_{L} \\
d_{C B_{8}}^{b_{i}} & :=d_{C B_{6}}^{b_{i}}-\tilde{d}_{H}+d_{M_{1}}^{b_{i}}=\alpha_{M}^{b_{i}} L_{M} R_{L}+d_{C B}^{b_{i}} R_{C B} .
\end{aligned}
$$

Household and bank balance sheets are given in Table 11.

\section{Stage E, substage 5: repayment of loans by firms using MT}

Firms using MT pay back their loans, and bank deposits are destroyed. Household and bank balance sheets are given in Table 12 .

\section{Stage E, substage 6: offsetting CB asset against CB liabilities}

Banks offset their $\mathrm{CB}$ assets against their $\mathrm{CB}$ liabilities. Using the expression of bank profits given by Equation (9), we obtain

$$
\begin{aligned}
& d_{C B_{7}}^{b_{j}}-l_{C B_{4}}^{b_{j}}=\alpha_{M}^{b_{j}} L_{M} R_{L}-\left(\alpha_{M}^{b_{j}}-1\right) L_{M} R_{C B}-\left(\left(L_{M}-E_{B}\right) R_{D}+\Pi_{B}^{b_{j}}\right)=0, \\
& d_{C B_{8}}^{b_{i}}-l_{C B_{3}}^{b_{i}}=\alpha_{M}^{b_{i}} L_{M} R_{L}+\left(1-\alpha_{M}^{b_{i}}\right) L_{M} R_{C B}-\left(\left(L_{M}-E_{B}\right) R_{D}+\Pi_{B}^{b_{i}}\right)=0 .
\end{aligned}
$$

\section{Appendix 3: Interbank borrowing and lending}

In Appendix 3, we describe how banks settle payments between agents and how banks can borrow or lend to each other, thereby creating bank assets and liabilities. Finally, we consider the consequences of the interbank market in equilibrium for the gross rates of return on $\mathrm{CB}$ deposits and private deposits. 
Table 13 Balance sheets illustrating the interbank market (1/4)

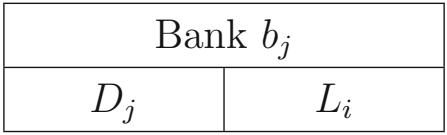

\begin{tabular}{|c|c|}
\hline \multicolumn{2}{|c|}{ Bank $b_{i}$} \\
\hline$L_{i}$ & $D_{j}$ \\
\hline
\end{tabular}

We use an example with two banks, $b_{j}$ and $b_{i}$. Assume that Bank $b_{i}$ grants a loan to Bank $b_{j}$. This creates four entries in the balance sheets, as illustrated by Table 13.

$L_{i}$ represents the amount of loans granted by Bank $b_{i}$ to Bank $b_{j}$, and $D_{j}$ the amount of deposits held by Bank $b_{j}$ at Bank $b_{i}$. The interbank market is competitive with a single gross rate of return for borrowing and lending. Since deposits owned by households and deposits owned by other banks cannot be discriminated, the corresponding gross rates of return both equal $R_{D}$.

We next investigate the relationship between $R_{C B}$ and $R_{D}$. Assume first that some buyers pay with their deposits at Bank $b_{j}$ and that the sellers deposit the money at Bank $b_{i}$. To settle the transfer, Bank $b_{j}$ has two options. If $R_{C B}<R_{D}$, it will apply for loans from the $\mathrm{CB}$ and deposit $\mathrm{CB}$ deposits at Bank $b_{i}$. Suppose now that $R_{C B}>R_{D}$. Then Bank $b_{j}$ becomes directly liable to Bank $b_{i}$. The buyers' deposits at Bank $b_{j}$ are replaced by a loan that Bank $b_{i}$ grants to Bank $b_{j}$. This loan is an asset for Bank $b_{i}$ that is matched by the liability corresponding to the new sellers' deposits. As assumed in Sect. 5.1.1, Bank $b_{i}$ has the right to require Bank $b_{j}$ to repay its liabilities with CB deposits, which Bank $b_{i}$ will do, as $R_{C B}>R_{D}$. At the end of the process, the balance sheets are identical, no matter whether Bank $b_{j}$ applied for a loan at Bank $b_{i}$ in the first place. Therefore, independently of $R_{D}$, the refinancing gross rate is equal to $R_{C B}$. However, assuming that no bank participating in the interbank market makes any loss by doing so requires that $R_{D}=R_{C B}$, which we show next.

Now we prove that $R_{D}=R_{C B}$. By contradiction, assume first that $R_{D}<R_{C B}$. Bank $b_{j}$, for example, would borrow from Bank $b_{i}$ at the gross rate of return $R_{D}$ and from the $\mathrm{CB}$ at the gross rate of return $R_{C B}$, as shown in the balance sheets in Table 14 .

Using deposits at Bank $b_{i}$, Bank $b_{j}$ can now repay CB liabilities. To carry out this payment, Bank $b_{i}$ has to borrow from the $\mathrm{CB}$ at the gross rate of return $R_{C B}$. The balance sheets are given in Table 15 .

Bank $b_{j}$ would profit from this process, whereas Bank $b_{i}$ would suffer losses. As we have assumed that taking part in the interbank market does not involve any loss from doing so, $R_{D}<R_{C B}$ cannot be sustained in any equilibrium with banks.

Now assume that $R_{C B}<R_{D}$. Then Bank $b_{j}$ would use CB deposits to repay its debt against Bank $b_{i}$. Such debt can always be created by bank $b_{j}$. This would end up with the balance sheets that are drawn up in Table 16.

Bank $b_{j}$ would profit from this process, whereas Bank $b_{i}$ would suffer losses. As we have assumed that taking part in the interbank market does not involve any loss from doing so, $R_{D}>R_{C B}$ cannot be sustained in any equilibrium with banks. ${ }^{39}$

\footnotetext{
39 Otherwise there could be sets of parameters where $R_{C B}>R_{D}$, and then no interbank lending would take place.
} 
Table 14 Balance sheets illustrating the interbank market (2/4)

\begin{tabular}{|c|c|}
\hline \multicolumn{2}{|c|}{ Bank $b_{j}$} \\
\hline$D_{j}$ & $L_{i}$ \\
$D_{C B}$ & $L_{C B}$ \\
\hline
\end{tabular}

\begin{tabular}{|c|c|}
\hline \multicolumn{2}{|c|}{ Bank $b_{i}$} \\
\hline$L_{i}$ & $D_{j}$ \\
\hline
\end{tabular}

Table 15 Balance sheets illustrating the interbank market (3/4)

\begin{tabular}{|c|c|}
\hline \multicolumn{2}{|c|}{ Bank $b_{j}$} \\
\hline$D_{C B}$ & $L_{i}$ \\
\hline
\end{tabular}

\begin{tabular}{|c|c|}
\hline \multicolumn{2}{|c|}{ Bank $b_{i}$} \\
\hline$L_{i}$ & $L_{C B}$ \\
\hline
\end{tabular}

Table 16 Balance sheets illustrating the interbank market (4/4)

\begin{tabular}{|c|c|}
\hline \multicolumn{2}{|c|}{ Bank $b_{j}$} \\
\hline$D_{j}$ & $L_{C B}$ \\
\hline
\end{tabular}

\begin{tabular}{|c|c|}
\hline \multicolumn{2}{|c|}{ Bank $b_{i}$} \\
\hline$D_{C B}$ & $D_{j}$ \\
\hline
\end{tabular}

\section{Appendix 4: Proofs}

Proof of Proposition 1 The social planner's maximization problem reads as follows:

$$
\begin{array}{ll} 
& \max _{\left\{K_{M}, K_{F}, I\right\}} u(W-I)+\delta u\left(f_{M}\left(K_{M}\right)+f_{F}\left(K_{F}\right)\right) \\
\text { s.t. } & \left\{\begin{array}{l}
0 \leq I \leq W, \\
0 \leq K_{F} \leq I, \quad \text { and } \quad I=K_{M}+K_{F} . \\
0 \leq K_{M} \leq I,
\end{array}\right.
\end{array}
$$

The Lagrangian for this maximization problem is

$$
L=u(W-I)+\delta u\left(f_{M}\left(I-K_{F}\right)+f_{F}\left(K_{F}\right)\right)-\lambda_{I}(I-W)-\lambda_{F}\left(K_{F}-I\right),
$$

where $\lambda_{I}$ and $\lambda_{F}$ denote the Lagrange parameters associated with the constraints $I \leq W$ and $K_{F} \leq I$. As $u, f_{M}$, and $f_{F}$ are concave, the objective function of the social planner's maximization problem is concave, and the constraints are linear. The Kuhn-Tucker conditions for an optimum are thus necessary and sufficient. By writing these conditions and solving for the system, we will thus find all possible solutions. The system of equations is 


$$
\left\{\begin{array}{ccc}
\frac{\partial L}{\partial I} \leq 0, & 0 \leq I, & I \frac{\partial L}{\partial I}=0 \\
\frac{\partial L}{\partial K_{F}} \leq 0, & 0 \leq K_{F}, & K_{F} \frac{\partial L}{\partial K_{F}}=0 \\
0 \leq \lambda_{I}, & I \leq W, & \lambda_{I}(W-I)=0 \\
0 \leq \lambda_{F}, & K_{F} \leq I, & \lambda_{F}\left(K_{F}-I\right)=0
\end{array}\right.
$$

where

$$
\begin{aligned}
\frac{\partial L}{\partial I} & =-u^{\prime}(W-I)+\delta u^{\prime}\left(f_{M}\left(I-K_{F}\right)+f_{F}\left(K_{F}\right)\right) f_{M}^{\prime}\left(I-K_{F}\right)-\lambda_{I}+\lambda_{F}, \\
\frac{\partial L}{\partial K_{F}} & =\delta u^{\prime}\left(f_{M}\left(I-K_{F}\right)+f_{F}\left(K_{F}\right)\right)\left(f_{F}^{\prime}\left(K_{F}\right)-f_{M}^{\prime}\left(I-K_{F}\right)\right)-\lambda_{F} .
\end{aligned}
$$

We first deal with the two following boundary cases: $I=0$ and $I=W$.

- Assume first that $I=0$. Then $\lambda_{I}=K_{F}=0$ and

$$
\frac{\partial L}{\partial I}=-u^{\prime}(W)+\delta u^{\prime}(0) f_{M}^{\prime}(0)+\lambda_{F}>0,
$$

as $u^{\prime}(0)=f_{M}^{\prime}(0)=\infty$. Inequality (19) contradicts $\frac{\partial L}{\partial I} \leq 0$, and no set of variables with $I=0$ can be optimal.

- Assume now that $I=W$. Then $\frac{\partial L}{\partial I}=0$, which also writes

$$
-u^{\prime}(0)+\delta u^{\prime}\left(f_{M}\left(W-K_{F}\right)+f_{F}\left(K_{F}\right)\right) f_{M}^{\prime}\left(W-K_{F}\right)-\lambda_{I}+\lambda_{F}=0 .
$$

As $f_{M}\left(W-K_{F}\right)+f_{F}\left(K_{F}\right)>0$ for all $K_{F} \in[0, W]$ and $u^{\prime}(0)=\infty$, Equation (20) cannot hold, and no set of variables with $I=W$ can be optimal.

In the remainder of the proof we thus assume that $I \in(0, W)$. This implies that

$$
\frac{\partial L}{\partial I}=0 \quad \text { and } \quad \lambda_{I}=0 .
$$

We now deal with the two boundary cases $K_{F}=0$ and $K_{F}=I$.

- Assume now that $K_{F}=0$. Then we obtain $\lambda_{F}=0$ and

$$
\frac{\partial L}{\partial K_{F}}=\delta u^{\prime}\left(f_{M}(I)\right)\left(f_{F}^{\prime}(0)-f_{M}^{\prime}(I)\right) \leq 0
$$

which implies that

$$
f_{M}^{\prime}(I) \geq f_{F}^{\prime}(0)
$$

Our assumption that $f_{F}^{\prime}(0)=\infty$ contradicts $\frac{\partial L}{\partial K_{F}} \leq 0$. Therefore, no set of variables with $K_{F}=0$ can be optimal.

- Assume first that $K_{F}=I$. Then we obtain 


$$
\frac{\partial L}{\partial K_{F}}=\delta u^{\prime}\left(f_{F}(I)\right)\left(f_{F}^{\prime}(I)-f_{M}^{\prime}(0)\right)-\lambda_{F}=0 .
$$

Moreover, the constraint $\lambda_{F} \geq 0$ implies

$$
f_{F}^{\prime}(I) \geq f_{M}^{\prime}(0) .
$$

Our assumption that $f_{M}^{\prime}(0)=\infty$ contradicts $\lambda_{F} \geq 0$. Therefore, no set of variables with $K_{F}=I$ can be optimal.

In the remainder of the proof we thus assume that $K_{F} \in(0, I)$. This implies that

$$
\frac{\partial L}{\partial K_{F}}=0 \quad \text { and } \quad \lambda_{F}=0 .
$$

We then obtain the following system of equations:

$$
\begin{gathered}
u^{\prime}(W-I)=\delta u^{\prime}\left(f_{M}\left(I-K_{F}\right)+f_{F}\left(K_{F}\right)\right) f_{M}^{\prime}\left(I-K_{F}\right), \quad \text { and } \\
f_{F}^{\prime}\left(K_{F}\right)=f_{M}^{\prime}\left(I-K_{F}\right) .
\end{gathered}
$$

In Equation (22), the left-hand side is strictly decreasing and the right-hand side strictly increasing in $K_{F}$. Moreover, as $f_{M}^{\prime}(0)=f_{F}^{\prime}(0)=\infty$, the left-hand side is larger than the right-hand side for values of $K_{F}$ small enough and smaller than the right-hand side for values of $K_{F}$ close enough to $I$. Therefore, as both sides in Equation (22) are continuous in $K_{F}$ strictly decreasing and strictly increasing, respectively, the Intermediate Value Theorem applies, and for all $I \in(0, W)$ there exists a unique solution $K_{F} \in(0, I)$ to Equation (22), which we denote by $K_{F}(I)$. Now we can re-write Equation (21) as follows:

$$
u^{\prime}(W-I)-\delta u^{\prime}\left(f_{M}\left(I-K_{F}(I)\right)+f_{F}\left(K_{F}(I)\right)\right) f_{M}^{\prime}\left(I-K_{F}(I)\right)=0 .
$$

We denote the left-hand side of Equation (23) by $g(I)$ where $I \in(0, W)$, and we calculate

$$
\begin{aligned}
g^{\prime}(I)= & -u^{\prime \prime}(W-I) \\
& -\delta u^{\prime}\left(f_{M}\left(I-K_{F}(I)\right)+f_{F}\left(K_{F}(I)\right)\right) f_{M}^{\prime \prime}\left(I-K_{F}(I)\right)\left(1-\frac{\partial K_{F}}{\partial I}\right) \\
& -\delta u^{\prime \prime}\left(f_{M}\left(I-K_{F}(I)\right)+f_{F}\left(K_{F}(I)\right)\right)\left(f_{M}^{\prime}\left(I-K_{F}(I)\right)\right)^{2}\left(1-\frac{\partial K_{F}}{\partial I}\right) \\
& -\delta u^{\prime \prime}\left(f_{M}\left(I-K_{F}(I)\right)+f_{F}\left(K_{F}(I)\right)\right) f_{M}^{\prime}\left(I-K_{F}(I)\right) f_{F}^{\prime}\left(K_{F}(I)\right) \frac{\partial K_{F}}{\partial I} .
\end{aligned}
$$

From Equation (22) we obtain

$$
\frac{\partial K_{F}}{\partial I}=\frac{f_{M}^{\prime \prime}\left(I-K_{F}\right)}{f_{M}^{\prime \prime}\left(I-K_{F}\right)+f_{F}^{\prime \prime}\left(K_{F}\right)}
$$

and hence 


$$
0 \leq \frac{\partial K_{F}}{\partial I} \leq 1
$$

From this relation and the concavity of $u, f_{F}$, and $f_{M}$, we conclude that $g^{\prime}(I)>0$. Moreover,

$$
\lim _{I \rightarrow 0} g(I)=-\infty \quad \text { and } \quad \lim _{I \rightarrow W} g(I)=+\infty .
$$

The Intermediate Value Theorem therefore applies, and together with $g^{\prime}(\mathrm{I})>0$, it implies that there is a unique value $I \in(0, W)$ satisfying Equation (23).

From the previous analysis we can conclude that there exists a unique optimum allocation $\left(I, K_{M}, K_{F}\right)$ with $I \in(0, W)$ and $K_{F}, K_{M} \in(0, I)$, which is given by the following system of equations:

$$
\left\{\begin{array}{ccc}
u^{\prime}(W-I) & = & \delta u^{\prime}\left(f_{M}\left(I-K_{F}\right)+f_{F}\left(K_{F}\right)\right) f_{M}^{\prime}\left(I-K_{F}\right), \\
f_{F}^{\prime}\left(K_{F}\right) & = & f_{M}^{\prime}\left(I-K_{F}\right) \\
I & = & K_{F}+K_{M} .
\end{array}\right.
$$

Proof of Lemma 1 The Lagrangian for this maximization problem is

$$
\begin{aligned}
L= & u(W-I)+\delta u\left(E_{B} R_{E}+D_{H} R_{D}+f_{F}\left(S_{F}\right)+f_{M}\left(E_{B}+D_{H}\right)-\left(E_{B}+D_{H}\right) R_{L}\right) \\
& -\lambda_{I}\left(E_{B}+D_{H}+S_{F}-I\right)-\gamma_{I}(I-W),
\end{aligned}
$$

where $\lambda_{I}$ and $\gamma_{I}$ denote the Lagrange parameters associated with the constraints $I=E_{B}+D_{H}+S_{F}$ and $W \geq I$. As $u$ is concave, the objective function of the households' maximization problem is concave. Moreover, the constraints are linear. The Kuhn-Tucker conditions for an optimum are thus necessary and sufficient. By writing these conditions and solving the system, we will therefore find all possible solutions. The system of equations reads 


$$
\left\{\begin{array}{cc}
\delta u^{\prime}\left(C_{1}\right)\left(R_{E}-R_{L}+f_{M}^{\prime}\left(E_{B}+D_{H}\right)\right)-\lambda_{I} \leq 0, & E_{B} \geq 0, \\
0=E_{B}\left(\delta u^{\prime}\left(C_{1}\right)\left(R_{E}-R_{L}+f_{M}^{\prime}\left(E_{B}+D_{H}\right)\right)-\lambda_{I}\right), & \\
\delta u^{\prime}\left(C_{1}\right)\left(R_{D}-R_{L}+f_{M}^{\prime}\left(E_{B}+D_{H}\right)\right)-\lambda_{I} \leq 0, & D_{H} \geq 0, \\
0=D_{H}\left(\delta u^{\prime}\left(C_{1}\right)\left(R_{D}-R_{L}+f_{M}^{\prime}\left(E_{B}+D_{H}\right)\right)-\lambda_{I}\right), & \\
\delta u^{\prime}\left(C_{1}\right) f_{F}^{\prime}\left(S_{F}\right)-\lambda_{I} \leq 0, & S_{F} \geq 0, \\
0=S_{F}\left(\delta u^{\prime}\left(C_{1}\right) f_{F}^{\prime}\left(S_{F}\right)-\lambda_{I}\right), & \\
-u^{\prime}(W-I)+\lambda_{I}-\gamma_{I} \leq 0, & I \geq 0, \\
0=I\left(-u^{\prime}(W-I)+\lambda_{I}-\gamma_{I}\right), & I \leq W, \\
\gamma_{I} \geq 0, & 0=\left(S_{F}+E_{B}+D_{H}-I\right) \lambda_{I} .
\end{array}\right.
$$

We first note that $I=0$ cannot be optimal. In this case, $E_{B}=D_{H}=S_{F}=\gamma_{I}=0$. We can re-write the first inequality of the system of equations as follows:

$$
\delta u^{\prime}(0)\left(R_{E}-R_{L}+f_{M}^{\prime}(0)\right) \leq \lambda_{I} .
$$

By assumption, $u^{\prime}(0)=f_{M}^{\prime}(0)=\infty$, which leads to a contradiction of optimality conditions.

Suppose now that $I=W$. In this case, $\frac{\partial L}{\partial I}=0$. This implies that $\lambda_{I}-\gamma_{I}=u^{\prime}(0)$. By assumption $u^{\prime}(0)=\infty$, so such a set of variables cannot be optimal.

We conclude that $I \in(0, W)$. Then $\gamma_{I}=0$ and $\frac{\partial L}{\partial I}=0$, which implies that

$$
\lambda_{I}=u^{\prime}(W-I)>0 .
$$

We also note that the conditions $E_{B}>0$ and $D_{H}>0$ imply that $R_{E}=R_{D}$. This is economically intuitive and follows from the first-order conditions

$$
\begin{aligned}
& 0=\delta u^{\prime}\left(C_{1}\right)\left(R_{E}-R_{L}+f_{M}^{\prime}\left(E_{B}+D_{H}\right)\right)-\lambda_{I}, \\
& 0=\delta u^{\prime}\left(C_{1}\right)\left(R_{D}-R_{L}+f_{M}^{\prime}\left(E_{B}+D_{H}\right)\right)-\lambda_{I} .
\end{aligned}
$$

We note that $S_{F}=0$ would require that $f_{F}^{\prime}(0) \leq \frac{\lambda_{I}}{\delta u^{\prime}\left(C_{1}\right)}$, which contradicts $f_{F}^{\prime}(0)=\infty .^{40}$ We conclude that households will choose $S_{F}>0$ and since $\mathrm{E}_{B}>0$,

\footnotetext{
${ }^{40}$ We note that the Inada conditions $f_{F}^{\prime}(0)=f_{M}^{\prime}(0)=\infty$ are sufficient conditions and are not necessary for an interior solution of the representative household's maximization problem. In this proof, necessary and sufficient conditions for an interior solution can be derived from $f_{F}^{\prime}(\bar{I})<f_{M}^{\prime}(0)$ and $f_{F}^{\prime}(0)>f_{M}^{\prime}(\underline{I})$, where $\bar{I}$ is the unique solution to the equation
}

$u^{\prime}(W-I)=\delta u^{\prime}\left(f_{F}(I)\right) f_{F}^{\prime}(I)$

and $\underline{I}$ is the unique solution to the equation

$u^{\prime}(W-I)=\delta u^{\prime}\left(f_{M}(I)\right) f_{M}^{\prime}(I)$ 
$D_{H}>0$, we have $S_{F}<I$. ${ }^{41}$ In the case where $E_{B}, D_{H}, S_{F}>0$, the previous system of equations implies the following relationships:

$$
\begin{gathered}
R_{E}=R_{D}, \\
R_{E}-R_{L}+f_{M}^{\prime}\left(I-S_{F}\right)=f_{F}^{\prime}\left(S_{F}\right), \\
f_{F}^{\prime}\left(S_{F}\right)=\frac{u^{\prime}(W-I)}{\delta u^{\prime}\left(C_{1}\right)} .
\end{gathered}
$$

We first solve Equation (25) with respect to $S_{F}$ for any $I>0$ given. For $S_{F}$ close to 0 , the right-hand side is larger than the left-hand side, and for $S_{F}$ close to $I$, the lefthand side is larger than the right-hand side. Moreover, the right-hand side is a strictly continuous and strictly decreasing function of $S_{F}$, and the left-hand side is a continuous and increasing function of $S_{F}$. Thus, the Intermediate Value Theorem applies, which, together with the properties mentioned above, shows that there exists a unique solution to Equation (25). We use $S_{F}^{*}(I)$ to denote it.

We re-write Equation (26) as follows:

$$
\begin{aligned}
f_{F}^{\prime}\left(S_{F}^{*}(I)\right) \delta u^{\prime} & \left(\left(I-S_{F}^{*}(I)-D_{H}\right)\left(R_{E}-R_{L}\right)\right. \\
& \left.+D_{H}\left(R_{D}-R_{L}\right)+f_{F}\left(S_{F}^{*}(I)\right)+f_{M}\left(I-S_{F}^{*}(I)\right)\right)=u^{\prime}(W-I) .
\end{aligned}
$$

By assumption, $I>0$ and $D_{H}<I-S_{F}^{*}(I)$-which has to hold as $E_{B}>0$. Then $I \in\left(D_{H}+S_{F}^{*}(I), W\right)$. For $I$ close to $W$, the right-hand side is larger than the lefthand side. For $I$ close to $D_{H}+S_{F}^{*}(I)$, the left-hand side is given at the limit by

$$
\left(R_{E}-R_{L}+f_{M}^{\prime}\left(D_{H}\right)\right) \delta u^{\prime}\left(D_{H}\left(R_{D}-R_{L}\right)+f_{F}\left(S_{F}^{*}\right)+f_{M}\left(D_{H}\right)\right)
$$

and the right-hand side by

$$
u^{\prime}\left(W-S_{F}^{*}-D_{H}\right) .
$$

When $D_{H}$ is close to zero and $D_{H}=I-S_{F}^{*}(I), S_{F}^{*}(I)$ is also close to zero by Equation (25), and the right-hand side of Equation (27) is smaller than the left-hand side. Therefore, as the right-hand side is strictly increasing and the left-hand side is strictly decreasing in $I$, the Intermediate Value Theorem applies for small values of $D_{H}$, and there exists a unique solution $I$ to Equation (27). We note that for Equations (25) and (26) to have a solution $\left(I, D_{H}, S_{F}\right), D_{H}$ has to fulfill

$$
\begin{aligned}
\left(R_{E}-R_{L}+f_{M}^{\prime}\left(D_{H}\right)\right) \delta u^{\prime}\left(D_{H}\left(R_{D}-R_{L}\right)\right. & \left.+f_{F}\left(S_{F}^{*}(I)\right)+f_{M}\left(D_{H}\right)\right) \\
& >u^{\prime}\left(W-S_{F}^{*}(I)-D_{H}\right),
\end{aligned}
$$

where $S_{F}^{*}(I)$ is the unique solution of Equation (25) for any given $I>0$.

\footnotetext{
$\overline{41}$ That $S_{F}<I$ follows also from our assumptions about utility and production functions.
} 
Proof of Lemma 2 Firms using FT and MT maximize shareholder value, and their demand for the physical good is derived from their maximization problems:

$$
\begin{array}{r}
\max _{K_{M} \in[0, I]}\left\{\max \left(f_{M}\left(K_{M}\right)-K_{M} R_{L}, 0\right)\right\}, \\
\text { and } \quad \max _{K_{F} \in[0, I]}\left\{\max \left(f_{F}\left(K_{F}\right)-K_{F} R_{F}, 0\right)\right\},
\end{array}
$$

and from our assumptions in Assumption 1.

Proof of Theorem 1 By Lemma 1, the representative household's portfolio choice requires that

$$
\begin{gathered}
R_{E}^{*}=R_{D}^{*} \quad \text { and } \\
R_{E}^{*}-R_{L}^{*}+f_{M}^{\prime}\left(I-S_{F}\right)=\frac{u^{\prime}\left(W-I^{*}\right)}{\delta u^{\prime}\left(C_{1}^{*}\right)},
\end{gathered}
$$

where

$$
\begin{aligned}
C_{1}^{*} & =E_{B}^{*} R_{E}^{*}+D_{H}^{*} R_{D}^{*}+f_{F}\left(S_{F}^{*}\right)+f_{M}\left(E_{B}^{*}+D_{H}^{*}\right)-\left(E_{B}^{*}+D_{H}^{*}\right) R_{L}^{*}, \\
I^{*} & =E_{B}^{*}+D_{H}^{*}+S_{F}^{*},
\end{aligned}
$$

and where $D_{H}^{*}$ is small enough such that

$$
\begin{aligned}
\left(R_{E}^{*}-R_{L}^{*}+f_{M}^{\prime}\left(D_{H}^{*}\right)\right) \delta u^{\prime}\left(D_{H}^{*}\left(R_{D}^{*}-R_{L}^{*}\right)\right. & \left.+f_{F}\left(S_{F}^{*}(I)\right)+f_{M}\left(D_{H}^{*}\right)\right) \\
& >u^{\prime}\left(W-S_{F}^{*}(I)-D_{H}^{*}\right) .
\end{aligned}
$$

A direct consequence of $R_{D}^{*}=R_{E}^{*}$, using the expression of profits in Equation (1), the definition of $R_{E}$, and the fact that households choose $D_{H}^{*}>0$ and $E_{B}^{*}>0$ yields

$$
R_{E}^{*}=R_{D}^{*}=R_{L}^{*}
$$

By using Equation (25), we then can restate Equation (29) as follows:

$$
f_{F}^{\prime}\left(S_{F}^{*}\right) \delta u^{\prime}\left(f_{F}\left(S_{F}^{*}\right)+f_{M}\left(E_{B}^{*}+D_{H}^{*}\right)\right)=u^{\prime}\left(W-I^{*}\right) .
$$

For given $R_{L}^{*}$ and $R_{F}^{*}$, firms demand $K_{M}^{*}=\hat{K}_{M}\left(R_{L}^{*}, I^{*}\right)$ and $K_{F}^{*}=\hat{K}_{F}\left(R_{F}^{*}, I^{*}\right)$, as given in Lemma 2. If $R_{L}^{*} \leq f_{M}^{\prime}\left(I^{*}\right)$, then $K_{M}^{*}=I^{*}$, and the equation $I^{*}=K_{M}^{*}+K_{F}^{*}$ would imply that $K_{F}^{*}=0$, which is not compatible with $f_{F}^{\prime}(0)=\infty$ by Lemma 2 . Thus, $R_{L}^{*}>f_{M}^{\prime}\left(I^{*}\right)$, and similarly we obtain $R_{F}^{*}>f_{F}^{\prime}\left(I^{*}\right)$. Hence, $R_{L}^{*}=f_{M}^{\prime}\left(K_{M}^{*}\right)$ and $R_{F}^{*}=f_{F}^{\prime}\left(K_{F}^{*}\right)$. As a consequence of $E_{\mathrm{B}}>0, D_{H}>0, S_{\mathrm{f}}>0$, we obtain $R_{E}=$ $R_{D}=R_{F}$. This, together with Equation (30), yields $R_{F}^{*}=R_{D}^{*}=R_{E}^{*}=R_{L}^{*}$. Moreover, using the market clearing condition for the physical good in $t=0$ given by

$$
K_{M}^{*}+K_{F}^{*}=I^{*}
$$

and $R_{L}^{*}=f_{F}^{\prime}\left(K_{F}^{*}\right)$, we can reformulate $K_{M}^{*}=\left(f_{M}^{\prime}\right)^{-1}\left(R_{L}^{*}\right)$ as 


$$
f_{F}^{\prime}\left(K_{F}^{*}\right)=f_{M}^{\prime}\left(I^{*}-K_{F}^{*}\right) .
$$

Finally, using $E_{B}^{*}+D_{H}^{*}=K_{M}^{*}$, Equation (31) can be reformulated as follows:

$$
u^{\prime}\left(W-I^{*}\right)=\delta u^{\prime}\left(f_{F}\left(K_{F}^{*}\right)+f_{M}\left(I^{*}-K_{F}^{*}\right)\right) f_{M}^{\prime}\left(I^{*}-K_{F}^{*}\right) .
$$

Equations (32), (33), and (34) are the equations characterizing the social planner's allocation in Proposition 1.

Finally, it is straightforward to verify that the tuples given in Theorem 1 constitute equilibria with banks as defined in Sect. 4.2.1.

Proof of Lemma 3 As set out in Sect. 5.1.1, the gross rate $R_{D}^{*}$ is used for borrowing and lending among banks. Similarly, as explained in Sect. 5.1.2, they can also borrow from, or deposit at, the $\mathrm{CB}$ at the policy gross rate $R_{C B}$. Suppose now by contradiction that $R_{D}^{*} \neq R_{C B}$. If $R_{D}^{*}<R_{C B}$, all banks would borrow from other banks and would use the deposits obtained to hold claims against the CB. Similarly, if $R_{D}^{*}>R_{C B}$, all banks would borrow from the $\mathrm{CB}$ and would use the $\mathrm{CB}$ deposits obtained to hold claims against other banks. As we have assumed that taking part in the interbank market does not involve any loss from doing so, both situations cannot be sustained in an equilibrium with banks. More detailed arguments are given in Appendix 3.

Proof of Proposition 3 Let $b \in[0,1]$ denote a bank. As $R_{D}=R_{C B}$ by Lemma 3, the shareholder value of Bank $b$ is given by

$$
\max \left(\alpha_{M}^{b} L_{M}\left(R_{L}-R_{C B}\right)+E_{B} R_{D}, 0\right) .
$$

We distinguish the following three cases:

- Assume that $R_{L}<R_{C B}$. The shareholder value of Bank $b$ decreases with $\alpha_{M}^{b}$. Thus, Bank $b$ 's choice is $\alpha_{M}^{b}=0$.

- Assume now that $R_{L}=R_{C B}$. The shareholder value of Bank $b$ does not vary with $\alpha_{M}^{b}$. Thus, Bank $b$ 's choice is $\alpha_{M}^{b} \in[0,+\infty)$.

- Assume finally that $R_{L}>R_{C B}$. The shareholder value of Bank $b$ increases with $\alpha_{M}^{b}$. Thus, Bank $b$ 's choice $\alpha_{M}^{b}$ is not finite.

The lending levels chosen by banks given the policy choice $R_{C B}$ as well as the gross rate $R_{L}$ can be summarized with the correspondence $\hat{\alpha}_{M}\left(R_{L}, R_{C B}\right)$ that is given in the proposition.

Acknowledgements We would like to thank Markus Althanns, Clive Bell, Volker Britz, Alex Cukierman, Hans Haller, Gerhard Illing and Pedro Pérez Velasco for very helpful comments. We are also grateful to seminar participants at the 45th Conference of the Committee for Monetary Economics of the German 
Economic Association, seminar participants at the Conference "Challenges to Monetary Policy in the Future", at the Swiss National Bank and at ETH Risk Center for useful discussions.

Funding Open Access funding provided by ETH Zurich.

Open Access This article is licensed under a Creative Commons Attribution 4.0 International License, which permits use, sharing, adaptation, distribution and reproduction in any medium or format, as long as you give appropriate credit to the original author(s) and the source, provide a link to the Creative Commons licence, and indicate if changes were made. The images or other third party material in this article are included in the article's Creative Commons licence, unless indicated otherwise in a credit line to the material. If material is not included in the article's Creative Commons licence and your intended use is not permitted by statutory regulation or exceeds the permitted use, you will need to obtain permission directly from the copyright holder. To view a copy of this licence, visit http:// creativecommons.org/licenses/by/4.0/.

\section{References}

Clower R (1967) A reconsideration of the microfoundations of monetary theory. Western Econ J 6:1-9

Dubey P, Geanakoplos J (1992) The value of money in a finite-horizon economy: a role for banks. In: Dasgupta P, Gale D, Hart O, Maskin E (eds) Economic analysis of markets and games: essays in honor of Frank Hahn. MIT Press, Cambridge, pp 407-444

Dubey P, Geanakoplos J (2003a) Inside and outside fiat money, gains to trade, and IS-LM. Econ Theory 21(2):347-397

Dubey P, Geanakoplos J (2003b) Monetary equilibrium with missing markets. J Math Econ 39(5-6):585-618

Dubey P, Geanakoplos J, Shubik M (2005) Default and punishment in general equilibrium. Econometrica 73(1): $1-37$

Espinoza R, Goodhart C, Tsomocos D (2009) State prices, liquidity, and default. Econ Theory 39:177-194

Faure S, Gersbach H (2016) Money creation and destruction. CFS working paper 555

Faure S, Gersbach H (2021) On the money creation approach to banking. Ann Finance 17:265-318

Gersbach H (2013) Bank capital and the optimal capital structure of an economy. Eur Econ Rev 64:241-255

Gersbach H (2021) The fragile triangle: Price stability, bank regulation and central bank reserves. CEPR Policy Insight No 112

Gersbach H, Haller H, Müller J (2015) The macroeconomics of Modigliani-Miller. J Econ Theory 157:1081-1113

Gurley J, Shaw E (1960) Money in a theory of finance. Brookings Institution, Washington, DC

Holmström B, Tirole J (1997) Financial intermediation, loanable funds, and the real sector. Q J Econ 112(3):663-691

Huber J, Shubik M, Sunder S (2014) Sufficiency of an outside bank and a default penalty to support the value of fiat money: experimental evidence. J Econ Dyn Control 47(C):317-337

Jakab Z, Kumhof M (2015) Banks are not intermediaries of loanable funds—and why this matters. Bank of England Working Paper 529

Kiyotaki N, Moore J (2003) Inside money and liquidity. Edinburgh school of economics discussion paper 115

Lin L, Tsomocos D, Vardoulakis A (2016) On default and uniqueness of monetary equilibria. Econ Theory 62(1):245-264

Lucas R (1982) Interest rates and currency prices in a two-country world. J Monet Econ 10:335-359

Martinez SJF, Tsomocos D (2018) Liquidity and default in an exchange economy. J Financ Stab 35:192-214

Shapley L, Shubik M (1977) Trade using one commodity as a means of payment. J Polit Econ 85(5):937-968 
Shi S (2002) Monetary Theory and Policy. In: Tian G (ed) Xiandai Jingji Xue Yu Jingrong Xue Qianyan Fazhan (translation: The Frontiers and Recent Developments in Economics and Finance). Shang Wu Press, Beijing, pp 131-209

Shubik M, Tsomocos D (1992) A strategic market game with a mutual bank with fractional reserves and redemption in gold. J Econ 55(2):123-150

Shubik M, Wilson C (1977) A theory of money and financial institutions. Part 30 (revised). The optimal bankruptcy rule in a trading economy using fiat money. Cowles Foundation discussion paper 424

Tobin J (1963) Commercial banks as creators of money. Cowles Foundation discussion paper 159

Walsh CE (2017) Monetary theory and policy, 4th edn. MIT Press, Cambridge (revised (First Edition: 1998))

Publisher's Note Springer Nature remains neutral with regard to jurisdictional claims in published maps and institutional affiliations. 